NBER WORKING PAPER SERIES

\title{
THE ECONOMICS OF WORK SCHEDULES UNDER THE NEW HOURS AND EMPLOYMENT TAXES
}

\author{
Casey B. Mulligan
}

Working Paper 19936

http://www.nber.org/papers/w19936

\author{
NATIONAL BUREAU OF ECONOMIC RESEARCH \\ 1050 Massachusetts Avenue \\ Cambridge, MA 02138 \\ February 2014
}

I appreciate the financial support of the George J. Stigler Center for the Study of the Economy and the State and the Hoover Institution, conversations with Trevor Gallen, and comments from seminar participants at Hoover. A spreadsheet with the paper's simulation model is available at marginaltaxrates.us. The views expressed herein are those of the author and do not necessarily reflect the views of the National Bureau of Economic Research.

NBER working papers are circulated for discussion and comment purposes. They have not been peerreviewed or been subject to the review by the NBER Board of Directors that accompanies official NBER publications.

(C) 2014 by Casey B. Mulligan. All rights reserved. Short sections of text, not to exceed two paragraphs, may be quoted without explicit permission provided that full credit, including $(\mathbb{C}$ notice, is given to the source. 
The Economics of Work Schedules under the New Hours and Employment Taxes

Casey B. Mulligan

NBER Working Paper No. 19936

February 2014, Revised March 2014

JEL No. E24,I13,J22

\begin{abstract}
$\underline{\text { ABSTRACT }}$
Hours, employment, and income taxes are economically distinct, and all three are either introduced or expanded by the Affordable Care Act beginning in 2014. The tax wedges push some workers to work more hours per week (for the weeks that they are on a payroll), and others to work less, with an average weekly hours effect that tends to be small and may be in either direction. A conservative estimate of the law's average employment rate impact is negative three percent. The ACA's tax wedges and ultimately its behavioral effects vary substantially across groups, with the elderly experiencing hardly any new disincentive and unmarried household heads experiencing tax wedges that are about twice the average. My estimates suggest that about four percent of the workforce will work less than the legislated 30-hour threshold solely to avoid the implicit and explicit full-time employment taxes.
\end{abstract}

\author{
Casey B. Mulligan \\ University of Chicago \\ Department of Economics \\ 1126 East 59th Street \\ Chicago, IL 60637 \\ and NBER \\ c-mulligan@uchicago.edu
}

An online appendix is available at:

http://www.nber.org/data-appendix/w19936 
For the first time in 2014, millions of workers face implicit federal taxes on their weekly work hours. More workers will face hours taxes in 2015 when assessable employers owe penalties on the basis of the number of full-time employees on their payroll. Both of these hours taxes are provisions of the Affordable Care Act of 2010 (hereafter, ACA), which also includes new implicit employment and income taxes on top of the longstanding taxes on incomes and payroll. This paper assesses the magnitude, direction, and economic characteristics of the hours, employment, and income tax wedges created by the ACA.

The tax wedge results are startling. Almost half of the working population is directly affected by at least one of the new incentives. The ACA's tax wedges vary substantially across groups, with the elderly experiencing hardly any new disincentive and unmarried household heads (including one-person households) experiencing tax wedges that are about twice the average. From an aggregate point of view, the employer penalties by themselves are historically significant but nonetheless the wedges that they create are matched, if not exceeded, by the ACA's implicit tax provisions. My results account for the facts that a variety of longstanding tax and subsidy rules also affect work incentives (in both directions) and that many people will not participate in programs for which they are eligible. ${ }^{1}$

This paper also uses a model from the literature to offer predictions for the magnitude, direction, and incidence of the long run effects of the ACA's various taxes on weekly work schedules. Work schedules are costly for both the model's employers and employees to adjust, but nonetheless the tax wedges push some workers to work more hours per week (for the weeks that they are on a payroll), and others to work less, with an average effect that tends to be small and can be in either direction. About a third of the employment effects and about half of the work schedule effects come from the ACA's employer penalties while the rest come from the law’s various implicit taxes.

\footnotetext{
${ }^{1}$ The income and payroll tax exclusions of premiums paid for employer-sponsored health insurance are among the many longstanding policies affecting the incentives to work.
} 
The ACA may increase weekly employment rates for some workers, but the average employment rate impact is significantly negative. Overall, weekly employment rates (not to be confused with the fraction of persons who work sometime during a calendar year) will be depressed by about three percent. Unmarried household heads will have log weekly employment rates depressed about twice as much as the average worker.

Section I explains how the ACA contains hidden taxes on work schedules, and quantifies the amount of the new incentives. Section II presents the model of labor market reactions. Section III points to the key behavioral magnitudes that are needed to project the market consequences of the new incentives, and relates the magnitudes to historical studies of the labor market and work schedules. Section IV displays the labor market projections, and Section V concludes.

\section{Distorting the Workweek}

\section{A. Relevant ACA Provisions}

Three major provisions of the ACA introduce incentives to change the workweek. The most acknowledged is the penalty on large employers that do not offer health insurance to their full-time employees. Because the amount of the penalty is proportional to the number of fulltime employees (over thirty) on the payroll, the penalty creates an incentive to substitute parttime positions for full-time positions. ${ }^{2}$

Less acknowledged is the ACA provision that full-time employees and their families cannot receive subsidized health coverage on the ACA's health insurance exchanges unless their employer fails to offer coverage. Except in the increasingly rare cases where part-time positions are eligible for employer health coverage too, an employee (and family) at a firm offering affordable coverage would be eligible for exchange subsidies only if he worked part-time, which

\footnotetext{
${ }^{2}$ The marginal penalty is either $\$ 2,000$, zero, or $\$ 40,000$ per full-time-employee year, depending whether the average number of full-time employees on the payroll during the calendar year is greater than, less than, or equal to, 49, respectively. The marginal penalty also depends on the number of full-time equivalent employees on the payroll in the prior "look back" calendar year. For simplicity, this paper models the employer penalty as if it had a constant marginal rate of $\$ 2,000$ without any look back. Gallen (2013) looks at the non-linearity of the penalty and how it relates to the allocation of labor between partand full-time positions.
} 
amounts to an implicit tax on full-time employment. ${ }^{3}$ The amount of the implicit tax on full-time employment is equal to the employee's valuation of the exchange subsidy he forgoes as a consequence of working full-time. This implicit tax has many of the economic characteristics of the employer penalty.

For any household head or spouse that has a family member (or himself) receiving exchange subsidies some time during the calendar year, the ACA also increases the marginal tax rate on their earnings and unemployment benefits because the exchange subsidies are phased out as a function of the sum of head and spouse income. Like any additional marginal income tax, this tax can reduce hours worked to the extent that employee work schedules have traditionally been lengthened in order to economize on employers' quasi-fixed costs of employment. Those quasi-fixed costs reduce employees' hourly taxable incomes, but high marginal tax rates make taxable income less valuable and thereby push employees to substitute shorter workweeks for higher hourly pay.

\section{B. The Direction of the Tax Wedges}

Before attempting to measure the magnitude of these incentives, it helps to see how the provisions might enter a household budget constraint. Take a large representative family that, in any given week, supplies $n$ workers each working $h$ hours. Its taxable labor income per worker is $w h-b-s(h)$, where $b>0$ is the quasi-fixed cost per worker that the employer passes on to employees and $s(h)$ is the employer penalty. The penalty is a step function of hours:

$$
s(h)=I\left(h_{i}>\underline{h}\right) s
$$

where $I()$ is the indicator function. $\underline{h}$ is the hours limit for "part-time" employment (that is, the hours limit for positions exempt from the penalty at assessable employers), which I take to be 29 hours per week. ${ }^{4}$

\footnotetext{
${ }^{3}$ See also Gamage (2012) and Mulligan (2013a). The incentives can be more complicated for dual-earner couples; see below my discussion of the ACA's "family glitch."

${ }^{4}$ The ACA sets the limit at 29 hours per week for hourly employees (i.e., 30-hour workers are considered full time), with some caveats noted below.
} 
The household pays a tax at constant rate $t+\tau$ on its labor income, where $\tau$ is the ACA component of the overall tax rate and $t$ is the non-ACA component, especially employee payroll taxes and employee personal income taxes. The household also incurs a per-employee commuting cost $a$. Finally, each of the employed family members pays a convex cost $f(h)$ of supplying hours and the household receives a lump sum transfer $g$ from the government. The household budget constraint is:

$$
c=g+\{(1-t-\tau)[w h-b-I(h>\underline{h}) s]-a-f(h)\} n
$$

where $c$ is household consumption. ${ }^{5}$

Holding constant total work hours $n h$, households face a tradeoff between hours and employment. High employment allows for fewer hours worked per employee and thereby less cost $f(h)$ of supplying hours per employee, but high employment creates more of the quasi-fixed costs. A reduction in the after-tax quasi-fixed costs, such as that achieved by a higher marginal earnings tax rate $\tau$, thereby encourages households to substitute employment for hours per employee.

If the household desired to be working full-time even under the ACA, then the employer penalty would just be another quasi-fixed cost and thereby encourage households to substitute hours for employment. If the household desired to be working part-time even without the ACA, then the relevant part of the budget set is not affected by the penalty and the household would have no incentive to adjust its behavior. Finally, households working full-time without the ACA but near the margin are induced to work part-time, but at a higher employment rate, in order to avoid the penalty.

In this way, the budget constraint alone suggests that an employer penalty might either reduce or increase average hours worked per employee. As $\underline{h}$ approaches zero - and is thereby well below desired hours - the employer penalty is essentially a tax on employees regardless of how many hours they work, and thereby shifts production in the direction of fewer employees

\footnotetext{
${ }^{5}$ The quasi-fixed cost $b$ includes forgone unemployment benefits (if any). For example, a person with no employer-borne quasi-fixed cost who receives taxable unemployment benefits in the amount UI whenever he is not working has the budget constraint $c=g+(1-t-\tau) U I+\{(1-t-\tau)[w h-U I-$ $I(h>\underline{h}) s]-a-f(h)\} n$, which, up to a constant, is the same as (2) with $b=U I$.
} 
each working longer hours. For $\underline{h}$ closer to desired hours, the penalty can also be avoided by reducing hours and not just employment, which by itself is a force in the direction of fewer hours per employee. As I show below, the net effect can be in either direction.

\section{The Magnitudes of the Tax Wedges: Five Scenarios}

There are five principle ACA-incentive scenarios for workers as of 2016, each of which is shown in Table 1. ${ }^{6}$ The first and most common is no (new) incentives: leaving employment or changing work hours has no effect on employer penalties owed and ACA subsidies received. This case has $\tau=s=0$. Each scenario has an overall marginal earnings tax rate of at least $t=$ $25 \%$, which is my estimate of a typical combined rate from personal income taxes (state and federal) and employee payroll taxes that are unrelated to the ACA.

The second scenario applies to workers for whom employer penalties are owed, but who do not receive subsidies regardless of their work status. For example, a penalty will be owed on a Medicare participant who works full time for a large employer not offering health insurance to its full-time employees. This person cannot participate in the ACA's exchanges because he is covered by Medicare. Because the employer penalties are not deductible from business income taxes, the salary equivalent of a $\$ 2,000$ employer penalty (adjusted for health cost inflation) is $\$ 3,144$ per year on the full-time payroll. $^{7}$

Although all workers in my model of weekly hours and employment have the same basic productivity, in reality the economic significance of a $\$ 3,144$ annual penalty (about $\$ 60$ per week) varies significantly across workers subject to the penalty because they differ widely in terms of their productivity. The dollar amount of the penalty probably reveals less about its typical significance than does the hours that a person would need to work just to raise the funds to pay the penalty. Appendix I shows that the 2012 median household head or spouse working 40 hours per week without employer-sponsored health insurance (hereafter, ESI), and with

\footnotetext{
${ }^{6}$ Mulligan (2013a) examines five other incentive scenarios, but in combination they contribute less than one tenth of a percentage point to the overall average marginal tax rate. For the purposes of this paper, I treat the other five scenarios as part of the "no new incentives" scenario, but this approximation may be inadequate for the purposes of examining specific groups, such as persons living close to the poverty line. ${ }^{7} 3,144=2,000 *\left(1.016^{2}\right) /[(1-0.39) *(1+0.0765)]$ where $39 \%$ and $7.65 \%$ are the employer business and payroll tax rates, respectively. The ACA indexes the employer penalty amount to health cost inflation after 2014; I assume that the growth rate is 1.6 percent per year in excess of wage growth between 2014 and 2016.
} 
positive earnings, and satisfying the exchange subsidy age and income eligibility criteria, has hourly wages and salaries that are about $\$ 14$. The employer penalty therefore amounts to just over 4 work hours per week for that median worker. ${ }^{8}$ Table 1 's second scenario therefore has $\tau$ $=0, t=25 \%$, and $s=4.2$ hours per week. ${ }^{9}$

A third scenario is a worker receiving exchange subsidies even when working full-time, but for an employer exempt from penalties. As a consequence of his receipt of the exchange subsidies, this worker faces an additional marginal tax rate on his earnings of about $23 \% .{ }^{10} \mathrm{~A}$ fourth scenario is such a worker receiving the subsidies but working for an employer subject to the penalty, which is the equivalent of 4.2 hours per week. Both of these scenarios have $\tau=$ $23 \%$, plus another 15 percentage points for non-ACA earnings taxes. The third and fourth scenarios have $s=0$ and 4.2 hours per week, respectively.

The fifth scenario is an employee who has ESI when working full-time and exchange subsidies otherwise. His marginal tax rate on earnings is the 23 percent rate (ACA component) noted above times the fraction of the year that he is not working full-time, which I take to be 0.034 based on the average fraction of the year that ESI workers (without access to ESI through a spouse) between 100 and 400 percent of the poverty line were at work in $2011 .{ }^{11}$ He also faces a new implicit tax on full-time work equal to the amount of the exchange subsidy he receives during periods when he is not working full-time.

\footnotetext{
${ }^{8}$ Appendix I explains why 4.2 hours per week may understate the significance of the penalty to the average worker experiencing it.

${ }^{9}$ The ACA penalties and exchange subsidies are determined on a monthly basis, even though the annualized subsidy amounts are a function of calendar year income. For simplicity, I assume that partial months of health insurance coverage are prorated in proportion to the number of weeks covered (and ignore the fact that months usually do not have an integer number of weeks) so that I can refer to weekly amounts of penalties and subsidies.

${ }^{10}$ The exchange subsidies are phased out with family income at an average rate of $24 \%$. However, the subsidies are advanced based on income estimates and roughly half of those receiving exchange subsidies during the year will receive amounts in excess of the amount consistent with the income they actually earned. The ACA includes another means-tested "premium reconciliation" program for forgiving the debt, and it has an average phase-out rate of about $4.5 \%$ that applies to roughly half of households getting subsidies (Mulligan 2013a). On the other hand, the ACA may prevent part of the population from relying on means-tested uncompensated care (Goolsbee 2011); the combination of these three rates is $23 \%$ (Mulligan 2013a).

${ }^{11}$ As noted above, the annualized subsidy falls, on average, \$23 for every additional $\$ 100$ earned for the calendar year. But a household participating in an exchange plan for a fraction of the year only gets the subsidy for that fraction of the year, which is why I calculate the average $\tau$ for the fifth scenario as $0.034 * 23 \%$.
} 
The dollar amount of the new implicit tax on full-time work varies among the workers who will face it, because those workers differ in terms of their family composition and in terms of their household income that determines the amount of the exchange subsidy foregone when not working. Moreover, as noted above, the economic significance of a given dollar amount also varies across workers. Appendix I shows that the salary equivalent of the exchange subsidy averages about three times the salary equivalent dollar amount of the employer penalty, which is typically about 2.7 hours per week in the sample of persons likely to face the new implicit tax on full-time work. ${ }^{12}$ Thus, assuming that ESI workers value the subsidies at $80 \%$ of their cost to the government, the fifth scenario has $\tau=0.8 \%$ and $s=6.4$ hours per week. ${ }^{13}$

Table 1's final column shows my estimates of the frequency of the scenarios among the population that would be working without the ACA sometime during the year. Based on Congressional Budget Office estimates, Mulligan (2013a) predicts that 26 percent of working non-elderly household heads and spouses will be at an employer that is either subject to the penalty or induced to keep its employment below the penalty-exemption cap. ${ }^{14}$ I assume that the same percentage applies to workers who are not household heads and spouses, so that the frequencies of the second and fourth scenarios must sum to 26 percent. Mulligan (2013a) finds that about 7 percent of non-poor non-elderly working heads and spouses will have family members receiving exchange subsidies during the calendar year. 72 percent of aggregate weeks worked are by all non-poor heads and spouses with non-elderly immediate family members, so the frequencies of the two exchange scenarios must sum to 5 percent. ${ }^{15}$ Among these I assume that two thirds work for employers subject to the employer penalty, which makes the frequencies on the third and fourth scenarios equal to two or three percent and the second scenario's frequency equal to 23 percent.

A large majority of workers are ineligible for exchange subsidies, and do not create a penalty liability for their employer, because the employer offers them health insurance. Among

\footnotetext{
${ }^{12}$ The ACA's exchange subsidies are paid in after-tax dollars, and the salary equivalent of one dollar after taxes is $1 /(1-t-\tau)$.

${ }^{13}$ The hourly equivalent amount is $6.4=3 * 2.7 * 0.8$. Also note that the sample of persons likely to face the new implicit full-time employment tax has greater average hourly earnings than the sample of persons likely to be subject to the employer penalty, which is why 4.2 hours per week (second row of Table 1) is not used to calculate the hours equivalent of the implicit full-time employment tax (last row of Table 1).

${ }^{14}$ For brevity, Table 1 refers to both categories as "penalized."

${ }^{15} 0.052=0.72 * 0.073$.
} 
these workers, most are ineligible for other reasons such as having access to coverage through a spouse or having household income above 400 percent of the poverty line, and therefore face the "no new incentives" scenario in Table 1. However, approximately 20 million of these workers are barred from obtaining exchange subsidies while working full-time solely because their employer offers coverage, which means that, for them, the ACA introduces an implicit full-time employment tax. These 20 million work somewhat more weeks per year than the average worker does, so their employment amounts to about 16 percent of weekly employment. ${ }^{16} 16 \%$ is therefore entered in the final row of Table 1 and the residual of $56 \%$ is entered in the top row.

Another way to measure the economic significance of the penalty and the implicit fulltime employment tax is to count the number of workers for whom changing to a 29-hour schedule would enhance their cash flow. For example, a penalized worker whose usual schedule is 33 hours per week would lose four hours of work by cutting hours to 29, but would save a 4.2hour penalty. Mulligan (2014) finds that, in 2016, about 1.7 percent of workers would have more disposable income with a 29-hour schedule than they would with their usual schedule of 30 hours or more. ${ }^{17}$ The data I use below suggests that 5.0 percent of workers in 2011 had usual weekly schedules greater than 29 hours but within four hours of 29 . If 26 percent of those (i.e., Table 1's combined frequency of the two penalty scenarios) had employers who would be willing to pay them the salary equivalent of the $\$ 2,000$ penalty in order to work less than 30 hours (or charge them that amount for the privilege of working more than 30 hours), that would be 1.3 percent of workers in my model who would have more disposable income with a 29-hour schedule than they would with their usual schedule of 30 hours or more. In this sense, Table 1 is conservative in terms of the economic significance of the employer penalty. ${ }^{18}$

In summary, one scenario just elevates marginal earnings tax rates, two scenarios primarily elevate quasi-fixed costs on full-time work, and a fourth scenario does both. All four scenarios involve economically significant changes in work incentives, and almost half of the

\footnotetext{
${ }^{16}$ In other words, weighted by weeks worked, 16 percent of workers satisfy all of three conditions: (a) cannot get ESI through a spouse, (b) has household income (inclusive of the cash value of employer insurance contributions) between 100 and 400 percent of the poverty line, and (c) either has ESI as part of a full-time position or work part-time (without ESI) for an employer offering ESI to full-time employees. I have not attempted to count the number of full-time workers who work for employers offering ESI and will enroll under the ACA, but as of 2012 had not enrolled and were uninsured; these workers should also be included in the bottom row of Table 1 .

${ }^{17}$ The percentage is more than three if work expenses are considered.

${ }^{18}$ Appendix I shows that the same is true for the implicit full-time employment tax (FTET).
} 
workforce experiences one of them. The two most common of the four scenarios are the two that elevate quasi-fixed costs of full-time employment. These two scenarios encourage work schedules of exactly 29 hours per week, especially among those whose weekly work hours would have been above but near that amount. Those who work full-time under the ACA are encouraged to work more hours per week and fewer weeks per year.

\section{A Model of the Distribution of Weekly Work Hours}

In addition to quantifying the size of the ACA's tax distortions related to the workweek, the purpose of this paper is to make predictions for the distribution of work hours under the ACA, with special attention to the fraction of employees working part-time and the propensity of workers to have schedules pushing the ACA-defined hours limit for part-time workers. I therefore extend the simple model (2) to acknowledge the fact that hours worked can vary across workers even when those workers face a common set of tax parameters. Hours and employment distributions are simulated from the extended model, once for each of the five scenarios in Table 1 .

\section{A. Equilibrium Defined}

A representative family consists of various types of persons who are heterogeneous in terms of their willingness to supply labor. Person types are indexed by $i \in[0,1]$. Without loss of generality, each type supplies the same aggregate work hours absent the ACA. The representative family's utility function is (3):

$$
\ln c-\frac{\eta}{\eta+1} \int_{0}^{1} \gamma_{i} N_{i}^{(\eta+1) / \eta} d i
$$

where the constant preference parameter $\eta>0$ is the Frisch wage elasticity of the supply of aggregate hours $N . \quad \gamma_{i}$ is a type-specific parameter reflecting preferences and the number of family members of each type.

The household budget constraint resembles the model (2) except that earnings, penalties, quasi-fixed costs, and hours supply costs are integrated across family members: 


$$
c=g+(1-t-\tau) \int_{0}^{1}\left[w_{i} h_{i}-b_{i p}-I\left(h_{i}>\underline{h}\right)\left(b_{i f}-b_{i p}\right)\right] n_{i} d i-\int_{0}^{1} n_{i}\left[f\left(h_{i} ; \bar{h}_{i}\right)+a\right] d i
$$

Note that the model is consistent with a discrete number of types merely by discretely partitioning the unit interval and assuming that $\gamma_{i}$ and $\bar{h}_{i}$ are constant within each partition.

I do not assume that employers pass on all of the quasi-fixed costs or employer penalties, which is why the model (4) has employees paying a different (implicit) employment fee to their employer $-b_{i p}$ or $b_{i f}$ - depending on their full- or part-time status. The hours supply cost function $f$ varies across types in a one-dimensional way related to the cost parameter $\bar{h}_{i}$. The hours cost function satisfies:

$$
f\left(\bar{h}_{i} ; \bar{h}_{i}\right)=0, f^{\prime}\left(\bar{h}_{i} ; \bar{h}_{i}\right)=0, f^{\prime \prime}\left(h_{i} ; \bar{h}_{i}\right)>0
$$

Each type of worker does a somewhat different task, and the composite gross output of the economy is a CES function of the worker inputs:

$$
A\left[\int_{0}^{1} N_{i}^{\frac{\sigma-1}{\sigma}} d i\right]^{\sigma /(\sigma-1)}-\int_{0}^{1} n_{i} b d i
$$

where the first term is gross output, $b \geq 0$ is the quasi-fixed cost of employing each worker of type $i$, and the constant $\sigma>0$ is the elasticity of substitution in production. The representative employer's profits are:

$$
A\left[\int_{0}^{1} N_{i}^{\frac{\sigma-1}{\sigma}} d i\right]^{\sigma /(\sigma-1)}-\int_{0}^{1}\left\{w_{i} N_{i}+\left[b-b_{i p}+I\left(h_{i}>\underline{h}\right)\left(s A+b_{i p}-b_{i f}\right)\right] n_{i}\right\} d i
$$

where, following the presentation in Table 1, the full-time employment tax is measured in work hours rather than units of the consumption good (the parameter $A$ converts hours to units of the consumption good). 
Given taste and technology parameters $\eta, \sigma, A, a, b$, and $\left\{\gamma_{i}\right\}$, and tax parameters $t, \tau, \underline{h}$ and $s$, a competitive equilibrium is a value $g$ for the lump sum transfer, mappings from type to marginal wages $w$, part-time employment fees $b_{p}$, full-time employment fees $b_{f}$, employment $n$, weekly hours $h$, and aggregate hours $N$, such that (i) each type's aggregate hours are the product of its employment and weekly hours; (ii) each type's employment and aggregate hours maximize profits (7) taking wages, lump sum transfers, penalties, and employment fees as given; (iii) each type's employment, weekly hours, and aggregate hours maximize (3) subject to $N_{i}=n_{i} h_{i}$ and (4), taking wages and employment fees as given; and (iv) the government budget constraint (8) balances:

$$
g=(t+\tau) \int_{0}^{1}\left[w_{i} h_{i}-b_{i p}-I\left(h_{i}>\underline{h}\right)\left(b_{i f}-b_{i p}\right)\right] n_{i} d i+\int_{0}^{1} I\left(h_{i}>\underline{h}\right) s A n_{i} d i
$$

Without loss of generality, types $i$ are ordered so that equilibrium weekly hours without the ACA $(\tau=s=0)$ are weakly increasing with $i$.

My model is similar to models by Rosen (1978), Calmfors and Hoel (1988), and Hart (1987), which have been used to examine the employment and hours consequences of a range of workweek policies, except that I put the cost of supplying weekly hours in the household budget constraint rather than the employer profit function and, most important for examining the ACA, allow for an equilibrium discontinuity in the household budget set. ${ }^{19}$

\section{B. Qualitative Results}

Equilibrium hours per type $i$ employee minimize costs per hour (9):

$$
x_{i} \equiv \min _{h} \frac{a+(1-t-\tau)\left[b_{i p}+I(h>\underline{h})\left(b_{i f}-b_{i p}\right)\right]}{h}+\frac{f\left(h ; \bar{h}_{i}\right)}{h}
$$

where $x_{i}$ denotes type $i$ 's minimum hourly cost.

\footnotetext{
${ }^{19}$ See also Oi (1962).
} 
Holding constant a type's aggregate work hours $N_{i}$, the profit function is linear in type $i$ employment, which means that the employer penalty and quasi-fixed costs must be passed to employees one-for-one:

$$
\begin{gathered}
b_{i p}=b \\
b_{i f}=b+s A
\end{gathered}
$$

If an employee's cost (9) is not minimized at the part-time threshold $\underline{h}$, then the optimum hours is an increasing function of $a+(1-t-\tau) b+I(h>\underline{h}) s A$, with the sensitivity of optimal hours determined by the degree of convexity of the cost function $f$. Without the ACA, this term would just be $a+(1-t) b$. Recall from the scenarios listed in Table 1 that the ACA either introduces $\tau>0$ or $s>0$, or both. The marginal tax rate hike by itself tends to reduce employment and weekly hours, whereas the penalty $s$ tends to reduce employment and increase hours among workers with hours above the penalty threshold. Of course, the penalty also induces workers whose optimal hours would be near but above the threshold to work below the threshold in order to avoid the (sometimes implicit) penalty.

A household's first order condition for type $i$ employment is:

$$
(1-t-\tau) w_{i}-x_{i}=c \gamma_{i} N_{i}^{1 / \eta}
$$

Combining the condition (11) with an employer's first order condition requires the distribution of aggregate hours across types satisfy (12):

$$
(1-t-\tau) A N_{i}^{-\frac{1}{\sigma}}\left[\int_{0}^{1} N_{i}^{\frac{\sigma-1}{\sigma}} d i\right]^{\frac{1}{\sigma-1}}=c \gamma_{i} N_{i}^{1 / \eta}+x_{i}
$$

Under any one of the four scenarios, the ACA affects weekly employment rates differently at different points in the hours distribution. Persons with high desired weekly hours (including those who would work 40 hours without the ACA) work fewer weeks and more hours per week as a result of a penalty on full-time work, while most persons induced to set hours at the threshold are working more weeks and fewer hours. The hike in marginal earnings tax rates reduces employment more among those with low desired hours because they have less surplus 
earnings beyond their quasi-fixed costs. As a result, the ACA has a composition effect on average hours per employee that can go in either direction.

Equation (12) also shows how the shape of the hours cost function $f$ affects the equilibrium profile for aggregate hours $N$ only through the profile for the hourly cost variable $x$. Combining (9) and (10), that profile is described by

$$
x_{i} \equiv \min _{h} \frac{a+(1-t-\tau)[b+I(h>\underline{h}) s A]}{h}+\frac{f\left(h ; \bar{h}_{i}\right)}{h}
$$

By the envelope theorem, the response of $x_{i}$ to a marginal change in the penalty amount $s$ depends only on $h_{i}$ and not the sensitivity of $h_{i}$ to the tax parameters (that is, the shape of the function $f$ ). Beginning from a given profile for weekly hours, a marginal change in $s$ will therefore have the same effect on the profile for aggregate hours regardless of whether equilibrium weekly hours are sensitive or insensitive to the penalty. Aggregate hours effects of infra-marginal changes in $s$ do depend on the shape of the cost function $f$, but only indirectly through the effect of $s$ on the distribution of weekly hours. For this reason, I expect the model results for aggregate hours to be fairly insensitive to quantitative assumptions about the shape of $f$.

\section{Model Calibration and Solution}

A number of the model parameters are related to the distribution of weekly work hours without the ACA, which I measure as the usual weekly work hours variable from the March 2012 Current Population Survey Annual Demographic File (hereafter, CPS). My CPS sample is any respondent working at least one week and at least eight hours per week during calendar year 2011, and observations are weighted by the product of weeks worked and the CPS March Supplement weight. ${ }^{20}$

The CPS reports a perhaps extraordinary fraction - about half - of workers who work exactly forty hours per week. If that fraction is exaggerated, it presents two possible problems

\footnotetext{
${ }^{20}$ Weighted by weeks worked, less than one percent of the CPS sample has usual weekly work hours less than 8. Among the remaining sample, 25 percent report usual weekly work hours less than 40 and 52 percent report exactly 40 .
} 


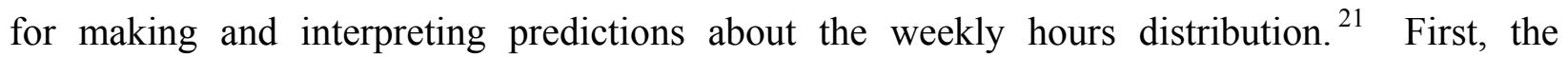
historical CPS data may understate the number of persons historically working 30-39 hours per week and thereby understate the number of persons who will be induced by the ACA to cut hours to 29 or less. Second, the ACA's measurement of work hours may, in the future, make CPS respondents more aware of the exact number of hours that they are working and thereby change reporting patterns in the CPS even if the ACA did not change behavior.

\section{A. Scalar Non-tax Parameters}

The model non-tax parameters consist of two distributions $\bar{h}_{i}$ and $\gamma_{i}$ for all $i \in[0,1]$, a function $f$ describing the costs of deviating from desired hours, and four scalars $\eta, \sigma$ and $a, b$ and two normalizations that pin down the productivity parameter $A$ and the mean of the taste parameter distribution. Table 2 lists the model's scalar non-tax parameters.

For the normalizations I set both employment and gross output without the ACA equal to one. Because model gross output without the ACA is the product of the productivity parameter $A$ and work hours per capita and the latter is normalized to be work hours per employee, I take $A$ to be the inverse of average weekly work hours per employee in the CPS, which is 39.8 .

My benchmark value for $\eta$ is 0.5 , which makes the wage elasticity of aggregate hours supply equal to about $0.57,{ }^{22}$ and also show results for alternative values $\eta=0$ and $\eta=0.88$. The $\eta=0$ case is not of much interest for obtaining final results, because incentives do matter, but it helps as an intellectual exercise to see how much of the ACA impact has to do with changing aggregate hours worked versus changing the composition of those hours among various groups and margins. My benchmark value of the elasticity of substitution between worker types is $\sigma=2$, based on Montgomery and Cosgrove's (1993) study of the degree of substitution between full-time and part-time positions, and also show results for an alternative values of $4 .^{23}$

\footnotetext{
${ }^{21}$ Time diary studies offer an alternative technique for measuring hours worked, but the diaries usually measure minutes worked per day rather than hours per week.

${ }^{22}$ Specifically, with $\eta=0.5$ and the other parameters set at their benchmark values, a consumptionconstant increase in the productivity parameter $A$ of the right amount to increase log average hourly earnings by 0.01 would increase log aggregate hours supplied by the median worker type (in terms of desired worker hours, i.e., the large group of people working exactly 40 hours but for the ACA) by 0.0057 .

${ }^{23}$ Montgomery and Cosgrove estimate a range of 1.7 to 2.6. They treat fringe benefits as a quasi-fixed cost for employers. In my opinion, only the administration of fringe benefits, and not the fringe benefits
} 
The parameter $a$, which denotes the common quasi-fixed costs paid by households, is set equal to $4.14^{*} \mathrm{~A}$ because 4.14 is the average weekly commuting hours among employed persons sampled by 2000 Census PUMS with positive weeks worked in $1999 .^{24}$ This is not to say that such costs are limited to commuting time or that commuting time is entirely a cost (part of it may be leisure time), but merely to establish the order of magnitude. I also show results for values of $a$ that are half and double the benchmark value.

The magnitude of the parameter $b$, which denotes the (non-ACA) quasi-fixed costs paid by employers, can be inferred from the earnings-hours relationship at a point in time. Formally, absent a tax that is specific to full-time work, pre-tax hourly employee compensation for a type $i$ working $h$ hours without the ACA is $(A-b / h)$, which means that, in theory, a given person moving from full-time to part-time would not only experience a cut in total pay, but also a cut in hourly pay. At least as a qualitative matter, this prediction seems to fit common experience. Moreover, economists have previously interpreted the relationship between hourly pay and hours worked in terms of quasi-fixed costs (Hirsch 2005), and have tried to estimate the causal effect of work hours on hourly pay. ${ }^{25}$ If the amount $\delta$ of the log hourly wage cut could be measured as a share of full-time hourly pay, then the measurement would permit us to estimate the magnitude of the quasi-fixed cost $b$ :

$$
\frac{b}{A h_{f}}=\frac{1-e^{-\delta}}{h_{f} / h_{p}-e^{-\delta}}
$$

themselves, are a quasi-fixed cost; the fringe benefits themselves are just a way that employees choose to spend their wages. Because the substitution elasticity is log quantity change per unit log cost change, I suspect that with lesser estimates of the quasi-fixed costs associated with fringe benefits, Montgomery and Cosgrove would have had greater estimates of the substitution elasticity. Also note that Owen's (1979) estimate (with macro data) of the substitution elasticity is 4.3.

${ }^{24}$ The Census asks about the number of minutes to travel to work, which I multiply by ten to get weekly commuting time for a 5-day-week schedule (a factor of two is to include the travel time from work to home). Sample observations are weighted by the Census person weight.

${ }^{25}$ Hirsch (2005) finds that workers switching from a full-time position to a part-time position lose a fulltime log hourly wage premium of about 0.09 , but he also reports specifications with a premium that is statistically indistinguishable from zero. Cross-sectional hourly wage comparisons, controlling for various demographic measures, sometimes find a premium greater than 0.09, other times find less. Most of these studies measure wages without including fringe benefits, and the little available evidence suggests that the log compensation premium for full-time work would be about 0.06 greater if fringe benefits were included because part-time employees are typically ineligible for the more valuable fringes like health insurance (Hirsch 2005, p. 546). 
where $h_{f}$ and $h_{p}$ are the hours worked on the full- and part-time positions being compared, respectively. Based on the literature cited in the previous footnote, I take $\delta=0.10$ as my benchmark value, and also show results for $\delta=0.05$ and $\delta=0.15$. I calibrate $h_{f}$ and $h_{p}$ as the CPS sample average weekly hours worked conditional on full- and part-time status, respectively, based on the definition of full-time used by the Bureau of Labor Statistics (at least 35 hours per week; hereafter, "BLS definition"). As a result, the benchmark value of $b$ is $0.09 *\left(A h_{f}\right)=4.11 * A$ and the overall non-ACA quasi-fixed costs are split almost exactly between employers and employees. $^{26}$

\section{B. Costs of Deviating from Desired Weekly Hours}

An important part of the cost function $f$ is its convexity, because that determines the sensitivity of weekly hours to quasi-fixed costs and the propensity to drop hours to 29 in order to avoid implicit and explicit penalties. It is also important that $f$ varies across worker types so that people in the same tax situation may nonetheless work different weekly hours. I therefore assume a two-parameter cost function of the form (15):

$$
f(h ; \bar{h})=A \frac{\bar{h}-h+h \ln \frac{h}{\bar{h}}}{\phi}
$$

where the ratio of constants $A / \phi>0$ indicates the slope and convexity of the relationship between hours and cost. $^{27} \bar{h}$ varies across worker types; $A / \phi$ does not.

To a second order approximation, equation (15) is proportional to the squared deviation $(h-\bar{h})^{2}$. I use (15) instead of the squared deviation because it results in a simple closed form solution for equilibrium hours per type $i$ employee in the absence of taxes specific to full-time employment $(s=0)$ :

$$
h_{i}=\bar{h}_{i}+[(1-t-\tau) b+a] \phi / A
$$

\footnotetext{
${ }^{26}$ This is not a statement about the ultimate economic incidence of quasi-fixed costs. The split between employer and employee, as defined above, matters because only the employer quasi-fixed costs are effectively deductible from income for the purposes of payroll and personal income taxation.

${ }^{27}$ In order to normalize units, I show the same parameter $A$ in the production and cost functions.
} 
In other words, equation (16) is the solution to the minimization problem (9) when $b_{i p}=b_{i f}=b, \mathrm{~s}$ $=0$, and $f$ takes the form (15). $\phi / A$ is the sensitivity of optimal weekly hours (per type $i$ employee) to the after-tax quasi-fixed cost when the cost is measured in consumption units.

$\phi$ is the sensitivity of optimal weekly hours to the after-tax quasi-fixed cost when the cost is measured in hours per week. As noted above, the $\$ 3,144 /$ year penalty is equivalent to the wages generated by 4.2 work hours per week, or about 3.2 hours after earnings taxes. Thus, my model assumes that the employment and work hours effects of the $\$ 3,144$ /year penalty for fulltime are essentially the same as they would be if full-time workers (by the ACA definition) were required to travel an extra 3.2 hours per week to and from work (i.e., about 19 minutes per oneway trip); both effects depend on the magnitude of $\phi$.

My model treats the "commuting cost" variable $a$ as a constant across workers, but equation (16) suggests that $\phi$ could be estimated by comparing weekly work hours to weekly commuting time across workers. I used the same 2000 Census PUMS sample as above, but limited to respondents with unallocated travel times, and regressed weekly work hours on weekly commuting hours. The coefficient on commuting hours was 0.258 , so I use $\phi=0.25$ as the benchmark value and also show results for alternative values $\phi=0.15$ and $\phi=0.35$.

\section{The Taste Distributions}

Having calibrated $b / A, a / A$, and $\phi$, inverting equation (16) with no-ACA tax parameters permits me to infer the cross-sectional distribution of the cost parameters $\left\{\bar{h}_{i}\right\}$ from the crosssectional CPS distribution of weekly hours in 2011:

$$
\bar{h}_{i}=\hat{h}_{i}-\left[(1-t) \frac{b}{A}+\frac{a}{A}\right] \phi
$$

where I put a hat over variables in order to indicate a no-ACA value. I measure no-ACA values for weekly hours from the March 2012 CPS.

As noted above, I define the type index $i$ such that each type supplies the same aggregate hours absent the ACA, $\widehat{N}$. Equation (12) therefore implicitly defines the profile of disutility parameters $\left\{\gamma_{i}\right\}$ : 


$$
\gamma_{i}=\frac{(1-t) A-\hat{x}_{i}}{\left(1-\widehat{N} \int_{0}^{1} \frac{f\left(\hat{h}_{j} ; \bar{h}_{j}\right)+a+b}{\hat{h}_{j}} d j\right) \widehat{N}^{\frac{1}{\eta}}}
$$

Note from equation (18) that, in principle, $\gamma_{i}$ could be negative, which means that type $i$ persons

would be willing to pay to be employed in a job with schedule $\bar{h}_{i}$, and in equilibrium would pay in the form of commuting costs and employment fees. However, this case rarely occurs in my quantitative results, and when it does it occurs in the far left tail $\left(1 / 1000^{\text {th }}\right.$ or so) of the distribution of hours taste parameters $\left\{\bar{h}_{i}\right\}$.

\section{Solution Technique and the Prevalence of "29ers"}

Weekly hours $h$ under the ACA can be calculated separately for each type and scenario from the minimization problem (9). Two of the scenarios (plus the no-new-tax scenario) have no penalty specific to full-time workers, so the first order condition (16) is sufficient to calculate equilibrium hours. For the other two scenarios, potential workers can be partitioned into two groups on the basis of weekly hours worked (conditional on employment) without the ACA. A critical hours value $\hat{h}_{k}$ determines the margin between the two groups and is implicitly defined by (19):

$$
1-\frac{\hat{h}_{k}-\tau b \phi / A}{\underline{h}}+\ln \frac{\hat{h}_{k}+[(1-t-\tau) s-\tau b / A] \phi}{\underline{h}}=0
$$

A person of type $k$ would work $\hat{h}_{k}$ hours without the ACA and thereby has the preferences that make him indifferent between working $\underline{h}$ hours penalty free under the ACA and working his optimal full-time job subject to the penalty $s$. Persons with non-ACA hours $\hat{h}<\hat{h}_{k}$ have ACA work hours equal to the minimum of $\underline{h}$ and the hours determined by the first order condition 
(16). Persons with $\hat{h}>\hat{h}_{k}$ have ACA work hours determined by the first order condition (16) with the quasi-fixed cost $b$ augmented to include the penalty $s A .^{28}$

Figure 1 graphs the solutions to equation (19) as a function of $\tau$ and $s .{ }^{29}$ It also shows the three scenarios from Table 1 that have penalties as a square, circle, and triangle. Figure 1's vertical axis measures the penalty in dollars per year. Its horizontal axis measures the critical value for weekly hours but for the ACA. For example, the triangle located at $(4.2,34.7)$ indicates that persons working more than 34.7 hours but-for the ACA would prefer to pay the 4.2 hour penalty and work full-time (ACA definition). Persons working less but-for the ACA would work part-time under the ACA, and in many cases do so by working exactly at the threshold $\underline{h}$. Those working exactly at the threshold are sometimes known as "29ers."

The larger the hours shown in Figure 1, the greater the percentage of workers who will work exactly at the threshold $\underline{h}$ under the ACA. For the workers at ESI employers who satisfy the other income and family criteria for exchange subsidies, and would value the exchange subsidies at $80 \%$ of their cost to the government, the critical value is shown as a square. The height of the square is 36.9 , which means that some of the "29ers" would be working 36 hours per week (when they are working) but for the ACA.

In order to solve for the distribution of employment rates under the ACA, I begin with a guess for ACA consumption $c$ and gross output $y$, conditional on one of the scenarios from Table 1. Equation (20) is solved type-by-type for the distribution of aggregate work hours $\left\{N_{i}\right\}$ :

$$
(1-t-\tau) A N_{i}^{-\frac{1}{\sigma}}\left(\frac{y}{A}\right)^{1 / \sigma}=\frac{(1-t) A-\hat{x}_{i}}{1-\widehat{N} \int_{0}^{1} \frac{f\left(\hat{h}_{j} ; \bar{h}_{j}\right)+a+b}{\hat{h}_{j}} d j} c\left(\frac{N_{i}}{\widehat{N}_{i}}\right)^{1 / \eta}+x_{i}
$$

Taking $n_{i}=N_{i} / h_{i}$, I then check whether the guesses for gross output and consumption are consistent with the solutions. If not, I revise the guesses and repeat until convergence. This iterative process is done once for each of the scenarios shown in Table $1 .^{30}$ The result of the

\footnotetext{
${ }^{28}$ Persons exactly at the margin work $\underline{h}$ under the ACA, but this never occurs in my data because nonACA hours are measured as exact integers and the critical value $\hat{h}_{k}$ is never an integer.

${ }^{29}$ A schedule for $\tau=0.8 \%$ is not shown because it is difficult to distinguish from the $\tau=0$ schedule.

${ }^{30}$ I use 92 types (one for each of the integer weekly hours amounts reported in the CPS, excluding 1-7) and revise the guesses by setting them to the consumption and gross output implied by the solutions to
} 
simulation is a competitive equilibrium as defined above because it satisfies the conditions stated in the equilibrium definition.

\section{E. Predictions for demographic groups}

The model allows for various possible impacts of the ACA on hours and employment because different tax scenarios are possible (see Table 1) and because the model is populated with a distribution of types that differ in terms of their desired weekly work hours. I use the model to make predictions for demographic groups by measuring the propensity of each group to supply hours without the ACA (as measured in the March 2012 CPS) and to experience each of the five tax scenarios. ${ }^{31}$ Appendix II shows the weights, but the primary features are (i) women are about $2 / 3$ of those working less than 40 hours per week (in 2011), and about 1/3 of those working more than 40, (ii) working household heads are especially likely to work more than 40 hours, regardless of marital status, but unmarried working household heads are also disproportionately represented in the 30-40 hour range, (iii) the working elderly are especially likely to work less than 30 hours, and (iv) that unmarried working household heads are almost three times as likely to forego the exchange subsidies as a consequence of working full-time at an employer offering ESI.

\section{Predictions for Work Schedules and Employment under the ACA}

\section{A. The Hours Distribution and Employment}

The law's impact on weekly hours worked per type $i$ employee is:

$$
\Delta h_{i}=\left\{\begin{array}{cc}
{\left[(1-t-\tau) s-\tau \frac{b}{A}\right] \phi} & \text { if } \hat{h}_{i}>\hat{h}_{k} \\
\min \left\{\underline{h}-\hat{h}_{i},-\tau \phi \frac{b}{A}\right\} & \text { if } \hat{h}_{i} \leq \hat{h}_{k}
\end{array}\right.
$$

(20) in the previous step. Convergence occurs in less than ten steps and all five scenarios combined can be calculated in less than one second on a PC.

${ }^{31}$ For the population as a whole, employment and aggregate hours under a tax scenario are unweighted cross-type integrals of the corresponding type-level variable. For a specific demographic group, the integrals are reweighted to reflect the group's representation among each type. 
where I use $\Delta$ to denote the "ACA impact" operation: the difference between an ACA outcome and its corresponding no-ACA outcome (indicated with hats). The top line is the impact among longer-hours employees: they work full-time even under the ACA. The first term in the min operator is the impact among workers with exactly $\underline{h}$ hours under the ACA, and would be working full-time absent the ACA. The second min term is for the remaining workers, who work part-time regardless of the ACA.

For each of the five tax scenarios, I calculate equilibrium distributions of employment and work hours, and then average the distributions using the weights shown in Table 1. Figure 2 shows the overall hours distribution with and without the ACA, excluding people who are not working during the week. ${ }^{32}$ Below 29 hours per week, there is little change in the hours distribution. Not surprisingly, the hours distribution under the ACA has less density between 30 and 35 hours than without the ACA because those are the worker types who can reduce hours below the ACA-defined threshold for full-time work, which is relevant for workers subject to employer penalties or workers who are ineligible for exchange subsidies solely because they have been offered ESI on a full-time job.

The right half of the hours distribution is shifted slightly to the right because the employer penalties and the exchange subsidies forgone by ESI workers are quasi-fixed costs of employment. People who prefer to work full-time can avoid penalties and/or enhance subsidies by working slightly more hours per week and fewer weeks per year.

Table 3 shows summary ACA-impact estimates. The top panel has a breakdown by tax scenario, and the bottom panel a breakdown by demographic group. The bottom row of each panel shows the total for all scenarios or groups combined. According to the benchmark model, the ACA reduces both employment and aggregate hours by about three percent. The effects on employment rates and aggregate hours are economically significant under the two most common scenarios - "penalty only" and "subsidy foregone due to ESI" - but nonetheless far less than under the (less common) middle two scenarios.

The final two columns quantify the bump in the hours distribution shown in Figure 2: 4.5 percentage points more of the workforce will work 26-29 hours per week - "the 29ers" - than

\footnotetext{
${ }^{32}$ Appendix II shows the results separately by scenario.
} 
would without the ACA. ${ }^{33}$ The final column shows that the percentage of workers under the ACA that are part-time by the BLS definition (that is, 34 hours per week or less) is within 2.6 points of the percentage without the ACA. This is another indicator that the frequency of 29ers can increase without increasing that much the fraction of workers working part time by the BLS definition.

The employment impacts of the ACA's quasi-fixed costs reflect two forces: (i) a tendency to substitute weekly hours for weekly employment, holding aggregate hours fixed, in order to economize on the ACA's quasi-fixed costs, and (ii) reductions in aggregate work hours due to a lost surplus from working. Figure 3 illustrates by showing the cross-sectional relationship between impacts on weekly work hours and weeks worked (both in logs) among persons experiencing the "subsidies foregone by ESI workers" tax scenario. If aggregate hours were held fixed, then the schedule in Figure 3 would be a straight line with slope equal to minus one. The fact that the schedule tends to be concave, with slopes closer to zero in the second quadrant and slopes further from zero in the fourth quadrant, means that aggregate hours impacts are more negative for worker types further from the origin in Figure 3. ${ }^{34}$ A negative effect of the ACA's penalties on aggregate work hours is to be expected given that workers either pay the ACA's taxes (implicit or explicit) or make costly behavioral adjustments to avoid those taxes.

\section{B. Average Hours per Employee: Offsetting Effects}

The middle columns of Table 3 show the ACA's impact on work hours per employee, by two measures. The first "VW" ("variable-weight") measure may be the most familiar because it just divides aggregate hours by the number of employees. However, this measure could be

\footnotetext{
${ }^{33}$ I use a slightly broader definition of "29er" to include those working 26,27 , or 28 hours per week because the threshold for salaried workers may be 4 days, rather than 30 hours, per week. The final rule issued by the U.S. Treasury states "For employees paid on a non-hourly basis (such as salaried employees), an employer may calculate the actual hours of service using the same method as for hourly employees, or use a days-worked equivalency crediting the employee with eight hours of service for each day for which the employee would be required to be credited with at least one hour of service.... The proposed regulations prohibit use of these equivalencies, however, in circumstances in which their use would result in a substantial understatement of an employee's hours of service..." (United States Department of Treasury 2014, pp. 22-23).

${ }^{34}$ The jump in the schedule reflects results for worker types in the far left tail of the desired hours distribution, among which the surplus for working (and thereby the sensitivity of their supply of aggregate hours) varies widely.
} 
affected by the ACA even if zero employees had the length of their workweek affected because employment rate impacts could be correlated with the length of the work week. The "IW" (initial-weight) measure averages type-specific weekly hours changes, using non-ACA employment rates as weights. By construction, this measure shows an impact only if the impact is nonzero for at least one type of worker. The IW measure is different from the VW measure to the extent that the ACA affects the composition of worker types among those employed during any given week.

Overall, both measures show essentially zero impact on weekly hours per employee because some worker types reduce their hours (conditional on employment), and other worker types increase it. However, the two measures are somewhat different at a scenario level because two scenarios have employment rates fall more for low-hours workers and the two others have employment rates fall more for high-hours workers. The former case is especially interesting because the model predicts that low-hours workers had little surplus from working before the $\mathrm{ACA}$, and the ACA's increase in the marginal tax rate eliminates them from the labor market. ${ }^{35}$

\section{Results by Demographic Group}

The bottom panel of Table 3 shows results for demographic groups, which are formed by changing the scenario and worker-type weights to match the group of interest, rather than for the population as a whole. Women (without regard to marital status) and unmarried household heads are especially likely to cut their hours to the ACA's hours threshold, both because they are disproportionately likely to otherwise work 30-35 hours and can therefore move to 29 hours with comparatively little cost. ${ }^{36}$ Unmarried heads are also more likely to have their exchange subsidy eligibility hinge on their ESI status, because by definition they do not have a spouse who could get them ESI coverage.

\footnotetext{
${ }^{35}$ To put it another way, to the extent that the model is wrong that the employment rates are especially sensitive among low-hours workers, then the IW measures are more informative than the VW measures.

${ }^{36}$ The 2011 distribution of weekly work hours by demographic group is shown in Appendix II. Throughout the paper, I assume that all groups have the same utility parameter $\eta$ that quantifies the wage elasticity of labor supply. If women's labor supply were significantly more elastic than men's, then Table 3 may understate the magnitude of the ACA's impact on women's employment and aggregate hours worked.
} 
Unmarried heads also have the most negative impact on their employment rates and weekly work hours. The elderly, defined to be persons in households in which the youngest person is at least 65 years old, have the impacts closest to zero because they cannot receive exchange subsidies regardless of how much they earn or work. The elderly may work at employers that are assessed the employer penalty, in which case they experience the "penalty only" tax scenario.

\section{Sensitivity Analysis}

In a way, the ACA full-time threshold of 30 hours per week strikes a balance between groups of workers reducing weekly hours and groups increasing them, resulting in entries for Table 3's middle two columns that are essentially zero. For this reason, the willingness of employers and employees to adjust work schedules does not matter much for determining the employment and hours effects. If adjustments are more costly than I assume, then the size of the downward hours adjustments would be smaller than I assume - there would be fewer 29ers - but the size of the upward adjustments would be less too, so the net weekly hours results would not be much different than shown in Table 3. Nonzero adjustments would occur in both directions, though, and by assumption the work schedule adjustments are costly, so that the ACA still significantly reduces the reward to employment even when employers or employees find work schedule adjustments to be costly. By the same reasoning, the results should not be much different if work schedule adjustments were less costly than I have assumed, except that the number of $29 \mathrm{ers}$ would be greater.

Table 4 confirms the intuition above. The top row of the table displays the results under my benchmark assumptions - namely the results shown in the bottom row of Table 3 . The next two rows show the results under two alternative assumptions about the employee costs of schedule adjustments. The following "high employer substitution" row shows results under the assumption that employers are easily (that is, with minimal loss of productivity) able to substitute part-time positions for full-time positions. ${ }^{37}$ Notice that the employment rate, aggregate hours, and average weekly hours columns are hardly different in rows (2)-(4) than they

\footnotetext{
${ }^{37}$ The elasticity of substitution in production is $\sigma=2$ in the benchmark and $\sigma=4$ in Table 4's fourth row.
} 
are under the benchmark. What varies more is the number of workers who become $29 \mathrm{ers}$ under the ACA, and the number of workers who work part-time under the BLS definition.

The next two rows of the table look at 34- and 35-hour thresholds for full-time work, rather than the 30-hour threshold that is in the law. Nobody becomes a 29er under the 34- and 35-hour thresholds, because a 29-hour schedule has no special advantage. However, with a 34hour threshold 13.2 percent of the workforce changes their work schedule from 34-plus hours to less than 34 hours (typically, they change to exactly 33 hours). Moreover, the middle columns of the table show that the 34-hour threshold no longer attains the balance between groups of workers reducing weekly hours and groups increasing them. The former groups dominate, and average weekly hours fall more than one percent. Employment rates fall less than one percent. With the 35-hour threshold, even workers who would otherwise be working 40 hours may find it worthwhile to cut their schedule by 6 hours in order to avoid the 5.6 hour quasi-fixed cost. It is even possible that aggregate employment rates increase. ${ }^{38}$ Thresholds greater than 30 hours result in less net government revenue (not shown in the table) than the actual 30-hour threshold, because the higher threshold encourages more workers to avoid the penalty or obtain the exchange subsidies.

The exchange plans through which households receive subsidies are not identical to employer plans, so it is possible that people value the exchange subsidies less than they cost the government. My benchmark assumption is that the valuation rate is 80 percent of government cost. Table 4's row (7) shows the result if the valuation rate were 50 percent instead.

Row (8) shows results that assume zero employer penalty. By comparison with row (1), row (8) suggests that the employer penalty is responsible for more than half of the 29ers but less than half of the employment and hours reductions.

The next four rows show alternative values for the quasi-fixed costs both on the employer and employee side. Increasing either quasi-fixed cost matters more for the ACA employment and aggregate hours impact estimates than decreasing the quasi-fixed costs because quasi-fixed costs cut heavily into the surplus of workers with low weekly hours. The ACA's impact on the

\footnotetext{
${ }^{38}$ As noted above, the CPS data show about half of workers working exactly forty hours per week in 2011, and gives little information as to how work schedule preferences might vary within that group. My model's quantitative predictions are therefore inaccurate when the gap between the full-time threshold and 40 is near to, or less than, the hourly amount of the full-time employment tax, as it is with the 35-hour threshold.
} 
prevalence of 29ers is insensitive to non-ACA quasi-fixed costs. Rows (13) and (14) show that a similar logic applies to the non-ACA marginal earnings tax rate $t$ : the ACA impact is somewhat more sensitive to increases to the rate than to decreases because the after-tax earnings share is already pretty small with the benchmark rate of 25 percent plus the ACA rates that apply in two of the tax rate scenarios.

The final row shows that the negative employment and aggregate hours impacts are about four percent when the model parameter $\eta$ is adjusted so that the Frisch elasticity with respect to the measured wage (net of employer-paid quasi-fixed costs) is assumed to be one for the median worker rather than the value of 0.57 it has with the benchmark parameters. ${ }^{39}$ However, the Frisch elasticity has little to do with the model's predictions for the prevalence of 29ers.

\section{Conclusions}

The Affordable Care Act has several economically distinct types of taxes that will affect work schedules. One is an explicit tax on full-time employment in an amount proportional to the number of full-time employees on the payroll, levied on employers that do not offer affordable health coverage to their full-time employees. The second, but not necessarily less important, is the full-time employment tax that is implicit in the fact that full-time employees at employers that $d o$ offer coverage are ineligible to receive subsidies on the law's new health insurance exchanges, whereas part-time employees (and persons not on any payroll) may get them. The third new tax is a combination of income taxes including the income tax implicit in the determination of the amount of the exchange subsidies. This paper emphasizes that income taxes are not the same as full-time employment taxes.

One contribution of this paper is to quantify the magnitude of the three types of new taxes, both in terms of fractions of the workforce that face them and the magnitudes experienced by those who do face the new taxes. In doing so, I account for the tendency of the ACA to move people off of means-tested uncompensated care, and the facts that (i) many people will not

\footnotetext{
${ }^{39}$ In this case $\eta=0.88$. If $\eta=0.88$ and the non-ACA earnings tax rate were $35 \%$ rather than $25 \%$, then the ACA's impact on log employment and log aggregate hours would be -0.046 and -0.045 , respectively (and not shown in Table 4), rather than the -0.040 and -0.039 shown in the last row of the table.
} 
participate in programs for which they are eligible, (ii) the ACA implicitly taxes unemployment benefits, and (iii) the ACA has a "family glitch" that prevents a number of married non-workers from getting subsidies. The ACA elevates income tax rates by more than 20 percentage points for part of the population, but that part of the population is small enough that the aggregate effects of either of the two new full-time employment taxes are probably more significant. On average, the ACA provisions considered in this paper will create a combined quasi-fixed cost of full-time employment of about 2.1 hours per week and, in addition, increase the average marginal earnings tax rate by 1.4 percentage points.

In theory, full-time employment taxes and income taxes reduce full-time employment, but their combined effect on weekly work hours is ambiguous. Employees who continue to work full-time schedules under the ACA have an incentive to work slightly more hours per week for fewer weeks. The law may also disproportionately reduce employment rates among persons who normally work short schedules, and thereby increase average work hours per employee by changing the composition of the workforce.

A second contribution of this paper is to estimate the long run impact of the new taxes on employment and the distribution of weekly work hours separately by demographic group by adapting and calibrating a model familiar from the labor economics literature. Not surprisingly, the model predicts that a large majority of the workforce works full time despite the new fulltime employment tax; these workers are induced to work fewer weeks and slightly longer workweeks than they would without the ACA. A smaller group makes a larger absolute change in their weekly work hours - in the direction of a shorter workweek - in order to avoid the fulltime employment taxes. Surprisingly, I predict that the ACA's overall impact on weekly work hours is close to zero.

In a way, the near-zero average weekly work hours effect reflects a balance created by the law's 30-hour threshold between groups that reduce their weekly hours and groups than increase it. But the near-zero average effect does not mean that the ACA fails to distort work schedules and their efficiency, just that the work schedule effects may not be detectable with aggregate data, even if that data were disaggregated according to the 35-hour definition of fulltime work that has been used by the Bureau of Labor Statistics over the years.

Both the full-time employment tax and the income tax significantly reduce the fraction of the population that is on a payroll in any given week. My conservative estimates suggest that the 
ACA will reduce the nationwide employment rate by three percent. These results are consistent with empirical studies of public policies that raise the relative employer cost of weekly work hours without creating a commensurate increase in employment because the average hour worked by employees is more expensive and/or less productive. ${ }^{40}$

These effects vary by demographic group. Unmarried household heads may reduce their employment rates by five percent. They will also be especially likely to work a schedule that keeps their hours just below the ACA threshold, but nevertheless their average weekly hours may noticeably increase as a consequence of the law.

According to the model, work behavior among the elderly will be hardly affected by the law. Women will be about twice as likely as men to have their weekly work hours pushed below 30 by the ACA.

At first glance, my predictions may seem at odds with Massachusetts' experience with the "Romneycare" health reform law signed by Governor Romney in 2006 because the evolution of the Massachusetts labor market after that date does not appear to be significantly different than in other states without health reforms (Dubay, Long and Lawton 2012). However, the labor taxes created by Romneycare and the ACA are qualitatively and quantitatively different from each other. The Romneycare employer penalty was proportional to total work hours at an employer, rather than the number of full-time employees as with the ACA's employer penalty, and was an order of magnitude less than the penalty in the federal law (Mulligan 2013b). Although both Romneycare and the ACA created subsidized health plans for persons who could not obtain coverage from their employer, Romneycare hardly introduced any new implicit employment tax because its subsidized coverage had a number of limitations and had been preceded by longstanding health assistance programs for the unemployed.

Both Romneycare and the ACA also created new opportunities for individuals to buy unsubsidized coverage apart from any employer. These opportunities are said to "unlock" workers from their full-time jobs: for example, permitting near-elderly workers to retire before they become eligible for Medicare, without losing health coverage (Gruber and Madrian 2004). In this view, the opportunities for unsubsidized coverage have many of the qualitative characteristics of an implicit full-time employment tax because the appearance of the coverage

\footnotetext{
${ }^{40}$ Some studies even find that raising the employer cost of weekly work hours reduces employment. See the literature surveyed by Hamermesh (1996a, Chapter 3) and Hamermesh (1996b, pp. 106-7).
} 
opportunities create a benefit for non-workers and part-time workers, but not for the typical fulltime worker who is already covered through employment. For the purpose of predicting the ACA's impacts on aggregate hours and the cross-sectional distribution of weekly hours, my Table 1 should show greater magnitudes and prevalence of implicit employment taxes. However, because (i) the literature on job lock does not offer much assistance on the magnitudes of those adjustments and (ii) the Romneycare experience suggests that the aggregate hours effects of creating opportunities to buy unsubsidized health coverage were not economically significant, I have not made any job-lock adjustments beyond those already represented by the taxes and subsidies included in Table $1 .^{41}$ This is another reason why one might interpret Table 3's hours and employment predictions as slightly conservative (see also Appendix I).

In separate work, a coauthor and I concluded that the ACA would reduce aggregate hours worked among non-elderly non-poor household heads and spouses by about three percent (Mulligan and Gallen 2013). The present paper models all hours worked, regardless of who supplies them, and its benchmark parameters suggest that aggregate hours fall 2.8 percent. Because non-elderly non-poor household heads supply only three quarters of aggregate hours, the Mulligan-Gallen estimate might be considered to be an aggregate hours impact of about 2.2 percent plus the response of the poor, elderly, and dependents to the employer penalties. ${ }^{42}$

\section{Appendix I: The FTET Distribution}

\section{A. Between demographic groups}

The hourly equivalents of both the employer penalty and the implicit full-time employment tax depend on a worker's hourly earnings because high hourly earning workers can earn a given dollar amount in fewer hours than low hourly earning workers. In addition, the dollar amount of the implicit full-time employment tax is related to the worker's weekly earnings because the exchange subsidies are means-tested. The purpose of this appendix is to show some of the heterogeneity of the implicit full-time employment tax among the population that will face that tax.

\footnotetext{
${ }^{41}$ See also Heim and Lurie (2014).

${ }^{42}$ But see Mulligan (2012) who suggests that the demand for low-skill workers increases with the employment rate of household heads and spouses; this effect is not included in the present paper and would increase the magnitude of the employment and hours effects.
} 
Table 5 lists the demographic groups represented in the final row of Table 1, in order of aggregate weeks worked in 2011, and represents all 20 million persons presented with an implicit FTET by the ACA (as measured in the March 2012 CPS and projected to 2016 assuming population growth of one percent per year). The top group is married households with dependents in which one spouse works full time with ESI and the other spouse either does not work full time or works for an employer that does not offer family coverage. ${ }^{43}$ Their average annualized subsidy forgone is shown in the right column and is almost $\$ 10,000$ after income and payroll taxes because of the number of family members whose exchange subsidy hinges on the job situation of the one family member who is working full time with ESI. ${ }^{44}$

A large number of married persons are represented in neither Table 5 nor Table 1's bottom row because many of their households have two earners, each with access to family coverage on the job. If one of the two spouses in such households were to give up his ESI by moving to part-time, the entire family would still be ineligible for exchange subsidies because the ACA requires that they obtain employer coverage through the spouse that continues to have access to family coverage on her job. ${ }^{45}$ This so-called "family glitch" thereby reduces the share of married people shown in Table 5, reduces the frequency of the ESI-worker scenario shown in Table 1, and increases the frequency of Table 1's "no new incentives" scenario. On the other hand, the family glitch increases the average subsidy amount (see the 6.4 hour entry in Table 1) because the work decision of an affected ESI worker has his entire family's exchange subsidy at stake.

The next two groups foregoing exchange subsidies are one-person households and singleparent households in which the head is working full time with ESI. According to the Kaiser premium calculator, annual silver plan premiums for a one-person household are about $\$ 5,000$,

\footnotetext{
${ }^{43}$ For married persons who are employed full time but enrolled in a spouse's plan, the availability of ESI at the employer is randomly imputed based on the size of that employer. $85 \%(8 \%)$ of not-enrolled employees at employers of 100 employees or more (less than 100), respectively, are assumed to have been offered coverage but turned it down.

${ }^{44}$ The averages in Table 4 includes zeros for the households that satisfy the eligibility criteria but have a premium that is cheap enough to be affordable by the ACA's definition.

${ }^{45}$ The family coverage offered by a spouse's employer does not even have to be affordable, as long as the spouse's employer offers affordable (by ACA definitions) self-only coverage to its employees. See Burkhauser, Lyons and Simon (2011) for further discussion of this so-called "family glitch."
} 
which means that the likely exchange subsidies are relatively small. ${ }^{46}$ However, as dependents are added to the household exchange subsidies increase significantly, and would be about $\$ 7,000$ annually for the average unmarried household with dependents and with income in the eligible range, as shown in the final column of Table 5.

The next group is married households with dependents in which one spouse has ESI and the other does not have a job offering ESI. It is smaller than the first two groups because many married households have two earners with access to ESI on their job. But the annualized exchange subsidies for married households that would satisfy the eligibility criteria when not working full time average about $\$ 8,300$. The top four groups together contain over 90 percent of the persons expected to face an implicit full-time employment tax under the ACA.

\section{B. Wage measurement error and the skewness of the distribution}

The hours equivalent of the implicit full-time employment tax - that is, the number of extra hours per week that a full-time ESI worker would have to work in order to add an amount to his after-tax income that was equal to the exchange subsidies he forgoes by having an ESI job - is related to the ratio of the dollar amount of the implicit full-time employment tax to wages and salaries (including fringes). The CPS data suggest that the distribution of the ratio of annualized exchange subsidies to annualized wages and salaries is skewed, and thereby suggest that the average ratio is high. Wage and salary measurement error contributes to the skewness in the ratio distribution because an underestimate of wage and salaries both leads to an overestimate of the numerator of the ratio and an underestimate of the denominator, and the latter effect is nonlinear and thereby not offset by wage overestimates.

In order to separate the two effects of wage and salary measurement error, Table 6 begins by showing the distribution of the hours equivalent of the employer penalty in the sample of CPS respondents estimated to face the implicit full-time employment tax. This sample is not subject to the employer penalty but the penalty's hours equivalent is of interest because the penalty is a fixed dollar amount. For example, the average weekly penalty among persons working 30-39 hours 3.2 hours per week, which exceeds the median of 2.7 hours largely because of the skewness induced by dividing by wages and salaries (including fringes).

\footnotetext{
${ }^{46}$ For example, a single person household with income of $\$ 30,000$ would get half of the premium subsidized, and no cost-sharing subsidy.
} 
The next part of the table shows the exchange subsidies as a ratio to the employer penalty, which is a ratio that is hardly affected by errors in measuring wages and salaries. Here a mean value of, say, 2.9, means that on average the salary equivalent of the exchange subsidies are 2.9 times the salary equivalent of the employer penalty. 2.9 times the penalty is about $\$ 9,200$ per year or $\$ 177$ per week. $^{47}$ At the sample median hourly wage (before payroll and income taxes), it takes about eight hours of work to earn $\$ 177$ in wages.

The third panel in Table 6 shows the hours equivalent of the exchange subsidy, calculated in two different ways: "uncorrected" and "corrected." The uncorrected refers to the sample mean or median of the distribution of the ratio of the weekly salary equivalent of the exchange subsidies forgone to weekly wages and salaries (including fringes), where the exchange subsidies foregone are converted to a salary equivalent by dividing by an income tax factor that is one minus 0.25 minus the ACA marginal tax rate times the fraction of weeks worked in 2011. Here the means significantly exceed the medians, as with, for example the full sample mean and median of 8.3 hours and 5.3 hours, respectively.

Each "corrected" exchange subsidy takes the median hours equivalent of the employer penalty shown in Table 6's second row and multiplies it by the exchange subsidy foregone (either mean or median) as a ratio to the employer penalty. For the entire sample, the corrected mean exchange subsidy foregone is equivalent to 7.7 hours per week and the median is equivalent to 6.4 hours per week. For the purpose of quantifying the number of 29ers, workers who normally work between 30 and 39 hours per week are especially interesting because they are likely to avoid full-time employment taxes by reducing their work hours. Their mean and median exchange subsidies foregone are 8.3 hours and 7.1 hours, respectively.

To the degree that households discount the value of the exchange subsidies relative to their cost, the discounts still need to be applied to Table 6. For example, if the full value of the exchange subsidy were eight hours per week, as it is for the corrected mean shown in Table 6, then the perceived value with an $80 \%$ valuation rate is 6.4 hours per week. My benchmark parameterization therefore assumes that the perceived value of exchange subsidies foregone is equivalent to 6.4 hours per week.

\footnotetext{
${ }^{47}$ The average annualized exchange subsidy foregone (including zeros for households for whom full-price insurance premiums are deemed affordable by the ACA) is about $\$ 6,800$ after payroll and personal income tax (see Table 5). The average salary equivalent of the foregone subsidy (calculated for each worker as the ratio of the after-tax subsidy foregone to $(1-t-\tau)$ is about $\$ 9,200$.
} 
The bottom panel of Table 6 is the same as the top panel, except that the bottom uses the sample of CPS workers that would be likely subject to the penalty. The hours equivalents are greater in the bottom panel because hourly wages are less in that sample.

Note that the full-value "corrected" average subsidy amount of 8.0 hours per week is less than the uncorrected averages shown in Table 6, and less than the average for persons working 30-39 hours in 2011 (and thereby especially likely to react to a full-time employment tax by reducing weekly hours to 29). Also note that the 4.2-hour penalty amount is less than all but one of the entries in the bottom panel of Table 6. These are two reasons why I interpret the results shown in Tables 2 and 3 of this paper to be conservative estimates of the employment and hours impacts of the ACA.

As noted in the text, another way to measure the economic significance of the implicit full-time employment tax is to count the number of workers for whom changing to a 29-hour schedule would enhance their cash flow. ${ }^{48}$ Mulligan (2014) finds that 2.4 percent of workers (the percentage is double if work expenses are considered) face an implicit FTET tax that is large enough that they would have more disposable income with a 29 -hour schedule than they would with their usual schedule of 30 hours or more. By comparison, the model in this paper, as calibrated with Table 1 with the full implicit FTET of 8.0 hours per week, implies that only 1.8 percent of persons who would be working but-for the ACA, both face an implicit FTET and had usual schedules greater than 29 but within eight hours of 29.

\section{Appendix II: Additional Statistics by Tax-Scenario and Demographic Group}

Figure 2 shows the weekly hours CDF for the "entire economy": that is, $65 \%$ no new incentives, $20 \%$ penalty-only scenario, 2 percent subsidy-only scenario, etc. (see Table 1). Figures $4 \mathrm{a}$ and $4 \mathrm{~b}$ show the CDFs for specific tax scenarios. The two most common scenarios

\footnotetext{
${ }^{48}$ Notice from Figure 1 that the critical tax amounts cross the 45-degree line because leisure time has value and because there are other ways to avoid the tax, which means that the effect of a 29-hour schedule on a worker's cash flow is neither necessary nor sufficient to determine whether a worker prefers to work 29 hours rather than his usual full-time schedule.
} 
are shown in Figure $4 \mathrm{a}$. A comparison of Figures $4 \mathrm{a}$ and $4 \mathrm{~b}$ show that the $4 \mathrm{a}$ scenarios also have the largest impacts on the hours CDF.

Table 7 shows the frequency weights used for each of the tax scenarios. The first column is copied from Table 1. The other columns show the scenario weights used for specific demographic groups. I assume that men and women have the same scenario weights. The elderly cannot receive exchange subsidies regardless of work status, so all of their weight is on the first two scenarios (I assume that the elderly are equally likely to work for a penalized employer as is the general population). Unmarried and married household heads are different in terms of the weights shown in the bottom row (and also in the top row, because the top row is a residual) for the reasons noted in Appendix I (see especially Table 5).

Figure 5 shows the demographic composition of persons working a specific number of weekly hours in 2011, as measured in the March 2012 CPS. For example, 5 percent of the 32 hours-per-week workers were elderly, 72 percent were female, 44 percent were married heads or spouses, and 20 percent were unmarried heads (these categories are not mutually exclusive). 


\section{Table 1. Five ACA-incentive scenarios}

Calendar year 2016. Includes both implicit and explicit taxes

\section{$\underline{\text { Scenario }}$}

No new incentives

Employer penalized, but employee not receiving exchange subsidies

Employee receiving exchange subsidies, but employer not penalized

Employee receiving exchange subsidies, and employer penalized

Worker at ESI employer without access to parttime own ESI or coverage through spouse

Frequency-weighted average

\section{Marginal earnings tax rate \\ $25 \%$}

$25 \%$

$48 \%$

$48 \%$

$26 \%$
Weekly penalty on full-

time work (hours equiv.) Frequency

$0 \quad 56 \%$

$4.2 \quad 23 \%$

$0 \quad 2 \%$

$4.23 \%$

$\underline{6.4} \quad \underline{16 \%}$

2.1

Notes: The marginal earnings tax rate includes pre-ACA payroll and personal income taxes at a $25 \%$ rate

"Receiving exchange subsidies" refers to heads or spouses of households receiving subsidies; dependents in such households are considered "not receiving" for the purpose of determining incentives. 
Table 2. Scalar non-tax parameter values

\section{parameter}

non-ACA gross output

non-ACA employment per capita

productivity, $A$

work disutility parameter, $\eta$

substitution elasticity in production, $\sigma$ household-paid quasi-fixed cost, $a$

employer-paid quasi-fixed cost, $b$

parameter of cost of desired hours deviations, $\phi$

$\begin{array}{rc}\text { benchmark value } & \text { alternate values } \\ 1 & \\ 1 & \\ 0.03 & \\ 0.5 & 0,0.88 \\ & \\ 2 & 4 \\ 4.14^{*} A & \text { half and double } \\ 4.11^{*} A & \text { less and greater }\end{array}$

0.25

\section{comments}

a normalization

a normalization

inverse of 2011 weekly work hours per employee approximately equal to the Frisch wage elasticity of aggregate hours supply

between worker types

lesser and greater values correspond to half and double the full-time hourly wage premium, respectively larger values of phi mean less convex costs/more weekly hours sensitivity

\section{Sources:}

2012 CPS Annual Demographic file

2000 Census PUMS

Montgomery and Cosgrove (1993)

Owen (1979)

Hirsch (2005) 


\section{Table 3. The ACA's Impact on Various Summary Labor Statistics}

Impacts by Tax Scenario ${ }^{(1)}$

$\underline{\text { Tax scenario }}$

Penalty only

Subsidy MTR only

Both

Subsidy foregone due to ESI

All (including no tax change)

$$
\log \mathrm{s}
$$

Weekly Aggregate Weekly hrs per employee Percentage of employees working:

$\begin{array}{rrrr}\text { emp. rate } & \underline{\text { hours }} & \underline{\mathrm{VW}} & \underline{\mathrm{IW}} \\ -0.039 & -0.039 & 0.000 & 0.007 \\ -0.163 & -0.158 & 0.004 & -0.006 \\ -0.215 & -0.204 & 0.011 & 0.003 \\ \underline{-0.066} & \underline{-0.064} & \underline{0.002} & \underline{0.012} \\ -0.028 & -0.028 & 0.001 & 0.003\end{array}$

\begin{tabular}{rr}
$26-29 \mathrm{hrs} / \mathrm{wk}$ & $1-34 \mathrm{hrs} / \mathrm{wk}$ \\
\hline 10.9 & 6.2 \\
0.0 & -1.3 \\
5.7 & -0.3 \\
$\underline{12.7}$ & $\underline{8.2}$ \\
\hline 4.6 & 2.6
\end{tabular}

Impacts by Demographic Group ${ }^{(1)}$

Demographic Group
Female
Male
Elderly
Unmarried head $^{(2)}$
Married head or spouse $^{(2)}$
All (including dependents and elderly)

\section{$\log s$}

Weekly Aggregate Weekly hrs per employee

$\begin{array}{rrrr}\text { emp. rate } & \underline{\text { hours }} & \underline{\mathrm{VW}} & \underline{\mathrm{IW}} \\ -0.026 & -0.028 & -0.002 & 0.003 \\ -0.031 & -0.028 & 0.003 & 0.009 \\ -0.006 & -0.009 & -0.003 & -0.001 \\ -0.051 & -0.048 & 0.003 & 0.008 \\ \underline{-0.033} & \underline{-0.030} & \underline{0.002} & \underline{0.009} \\ -0.028 & -0.028 & 0.001 & 0.003\end{array}$

Percentage of employees working:

\begin{tabular}{rr}
$26-29 \mathrm{hrs} / \mathrm{wk}$ & $1-34 \mathrm{hrs} / \mathrm{wk}$ \\
\cline { 2 - 2 } 3.9 & 3.2 \\
3.4 & 2.0 \\
3.6 & 2.1 \\
7.3 & 4.6 \\
$\underline{3.4}$ & $\underline{1.9}$ \\
4.6 & 2.6
\end{tabular}

Notes: ${ }^{(1)}$ Every table entry is a difference between the ACA outcome and the no-ACA outcome, and expressed in percentage points in the final two columns. VW impact (in logs) is the difference between the impacts for log aggregate hours and log employment rate. IW impact is the log change in weekly hours averaged across worker types (before logging) using nonACA employment shares as weights.

${ }^{(2)}$ Excludes poor and elderly workers 
Table 4. Sensivity Analysis

ACA Impacts under alternative assumptions ${ }^{\text {(a) }}$

\begin{tabular}{|c|c|c|c|c|c|c|}
\hline Assumption & emp. rate & hours & $\underline{\mathrm{VW}}$ & $\underline{\text { IW }}$ & $\underline{26-29 \mathrm{hrs} / \mathrm{wk}}$ & $1-34 \mathrm{hrs} / \mathrm{wk}$ \\
\hline (1) Benchmark & -0.028 & $\overline{-0.028}$ & 0.001 & 0.003 & 4.6 & 2.6 \\
\hline (2) Schedule adjustments are more costly & -0.030 & -0.028 & 0.001 & 0.003 & 3.1 & 1.2 \\
\hline (3) Schedule adjustments are less costly & -0.028 & -0.027 & 0.001 & 0.005 & 5.4 & 3.5 \\
\hline (4) High employer subst. between FT \& PT & -0.028 & -0.028 & 0.001 & 0.003 & 4.6 & 2.7 \\
\hline (5) 34-hour threshold rather than 30 & -0.004 & -0.022 & -0.017 & -0.013 & 0.0 & 13.2 \\
\hline (6) 35 -hour threshold rather than 30 & 0.023 & -0.016 & -0.038 & -0.033 & 0.0 & 27.2 \\
\hline (7) Lower subsidy valuation rate & -0.025 & -0.024 & 0.000 & 0.002 & 4.3 & 2.3 \\
\hline (8) ACA lacks employer penalty & -0.018 & -0.018 & 0.000 & 0.002 & 1.9 & 1.2 \\
\hline (9) Lower employer quasi-fixed cost & -0.027 & -0.026 & 0.001 & 0.004 & 4.6 & 2.6 \\
\hline (10) Half employee quasi-fixed cost & -0.025 & -0.025 & 0.000 & 0.003 & 4.6 & 2.7 \\
\hline (11) Higher employer quasi-fixed cost & -0.030 & -0.030 & 0.000 & 0.003 & 4.5 & 2.7 \\
\hline (12) Double employee quasi-fixed cost & -0.036 & -0.036 & 0.001 & 0.003 & 4.5 & 2.6 \\
\hline (13) Add ten points to non-ACA tax rate & -0.033 & -0.032 & 0.000 & 0.003 & 4.5 & 2.6 \\
\hline (14) Subtract ten points from non-ACA tax rate & -0.026 & -0.025 & 0.001 & 0.004 & 4.7 & 2.8 \\
\hline (15) Frisch aggregate hours elasticity $=1$ & -0.040 & -0.039 & 0.001 & 0.003 & 4.6 & 2.7 \\
\hline
\end{tabular}

$\operatorname{logs}$

Weekly Aggregate Weekly hrs per employee

Percentage of employees working:

Notes: ${ }^{(a)}$ Every table entry is a difference between the ACA outcome and the no-ACA outcome, and expressed in percentage points in impact is the log change in weekly hours averaged across worker types (before logging) using non-ACA employment shares as weights. 
Table 5. Demographic groups subject to the implicit FTET

\begin{tabular}{|c|c|c|c|c|c|}
\hline Marital status & Insurance/work status & Dependents & subject to implicit FTET & \multicolumn{2}{|c|}{ subsidy foregone } \\
\hline Married & FT ESI w/o access through spouse & spouse \& dependents & $32.7 \%$ & $\$$ & 9,557 \\
\hline Unmarried & FT ESI & one person household & $27.0 \%$ & $\$$ & 2,498 \\
\hline Unmarried & FT ESI & dependents & $25.1 \%$ & $\$$ & 6,761 \\
\hline Married & FT ESI w/o access through spouse & spouse, no dependents & $9.0 \%$ & $\$$ & 8,165 \\
\hline Unmarried & PT no-ESI, but FT coworkers have ESI & dependents & $1.9 \%$ & $\$$ & 9,143 \\
\hline Unmarried & PT no-ESI, but FT coworkers have ESI & one person household & $1.9 \%$ & $\$$ & 4,498 \\
\hline Married & PT no-ESI, but FT coworkers have ESI & all & $0.9 \%$ & $\$$ & 10,461 \\
\hline Married & FT ESI w/o access through spouse & spouse on Medicare & $1.5 \%$ & $\$$ & 6,065 \\
\hline & $\begin{array}{l}\text { Entire sample } \\
\end{array}$ & & $100.0 \%$ & $\$$ & 6,821 \\
\hline
\end{tabular}

Notes: FTET denotes the full-time employment tax. FT denotes full-time worker. ESI denotes employer-sponsored health insurance. Dollar amounts are in 2014 dollars after income and payroll taxes. 
Table 6. The distribution of FTET amounts

Usual weekly hours in 2011

\begin{tabular}{|c|c|c|c|c|}
\hline & & 30-39 & $\underline{40}$ & Any \\
\hline \multicolumn{5}{|c|}{ Sample facing an implicit FTET } \\
\hline \multirow{2}{*}{$\begin{array}{l}\text { Employer penalty, weekly } \\
\text { weekly hours equivalent }\end{array}$} & mean & 3.2 & 2.9 & 2.8 \\
\hline & median & 2.7 & 2.7 & 2.7 \\
\hline \multirow{2}{*}{$\begin{array}{l}\text { Exchange subsidy foregone } \\
\text { per } \$ \text { of employer penality }\end{array}$} & mean & 3.1 & 2.9 & 2.9 \\
\hline & median & 2.6 & 2.4 & 2.4 \\
\hline \multirow{4}{*}{$\begin{array}{l}\text { Exchange subsidy foregone, } \\
\text { weekly hours equivalent }\end{array}$} & uncorrected mean & 10.3 & 8.5 & 8.3 \\
\hline & uncorrected median & 7.2 & 6.2 & 5.5 \\
\hline & corrected mean & 8.3 & 7.9 & 7.7 \\
\hline & corrected median & 7.1 & 6.5 & 6.4 \\
\hline \multicolumn{5}{|c|}{ Working heads and spouses without own ESI in 2012} \\
\hline \multirow{2}{*}{$\begin{array}{l}\text { Employer penalty, weekly } \\
\text { weekly hours equivalent }\end{array}$} & mean & 5.4 & 7.8 & 5.8 \\
\hline & median & 4.4 & 4.2 & 3.8 \\
\hline
\end{tabular}

Notes: FTET denotes the full-time employment tax. The subsidy amounts in the table are valued at their full cost to the U.S. Treasury. The "corrected" subsidies are the product of the table's second row and either the third row (mean) or fourth row (median). 
Table 7. Tax-scenario weights by demographic group

\begin{tabular}{|c|c|c|c|c|c|c|}
\hline \multirow[b]{2}{*}{ Tax scenario } & \multicolumn{2}{|l|}{ Full } & \multicolumn{4}{|c|}{ Household heads \& spouses } \\
\hline & population & Men & Women & Elderly & Unmarried & Married \\
\hline No new incentives & $56 \%$ & $56 \%$ & $56 \%$ & $74 \%$ & $31 \%$ & $57 \%$ \\
\hline $\begin{array}{l}\text { Employer penalized, but employee not } \\
\text { receiving exchange subsidies }\end{array}$ & $23 \%$ & $23 \%$ & $23 \%$ & $26 \%$ & $21 \%$ & $21 \%$ \\
\hline $\begin{array}{l}\text { Employee receiving exchange subsidies, } \\
\text { but employer not penalized }\end{array}$ & $2 \%$ & $2 \%$ & $2 \%$ & $0 \%$ & $2 \%$ & $2 \%$ \\
\hline $\begin{array}{l}\text { Employee receiving exchange subsidies, } \\
\text { and employer penalized }\end{array}$ & $3 \%$ & $3 \%$ & $3 \%$ & $0 \%$ & $5 \%$ & $5 \%$ \\
\hline $\begin{array}{l}\text { Worker at ESI employer without access to } \\
\text { part-time own ESI or coverage through }\end{array}$ & $\underline{16 \%}$ & $\underline{16 \%}$ & $16 \%$ & $\underline{0 \%}$ & $\underline{41 \%}$ & $15 \%$ \\
\hline Total & $100 \%$ & $100 \%$ & $100 \%$ & $100 \%$ & $100 \%$ & $100 \%$ \\
\hline
\end{tabular}

Notes: "Receiving exchange subsidies" refers to heads or spouses of households receiving subsidies; dependents in such households are considered "not receiving" for the purpose of determining incentives. Household head and spouse categories excluded poor and elderly workers. 


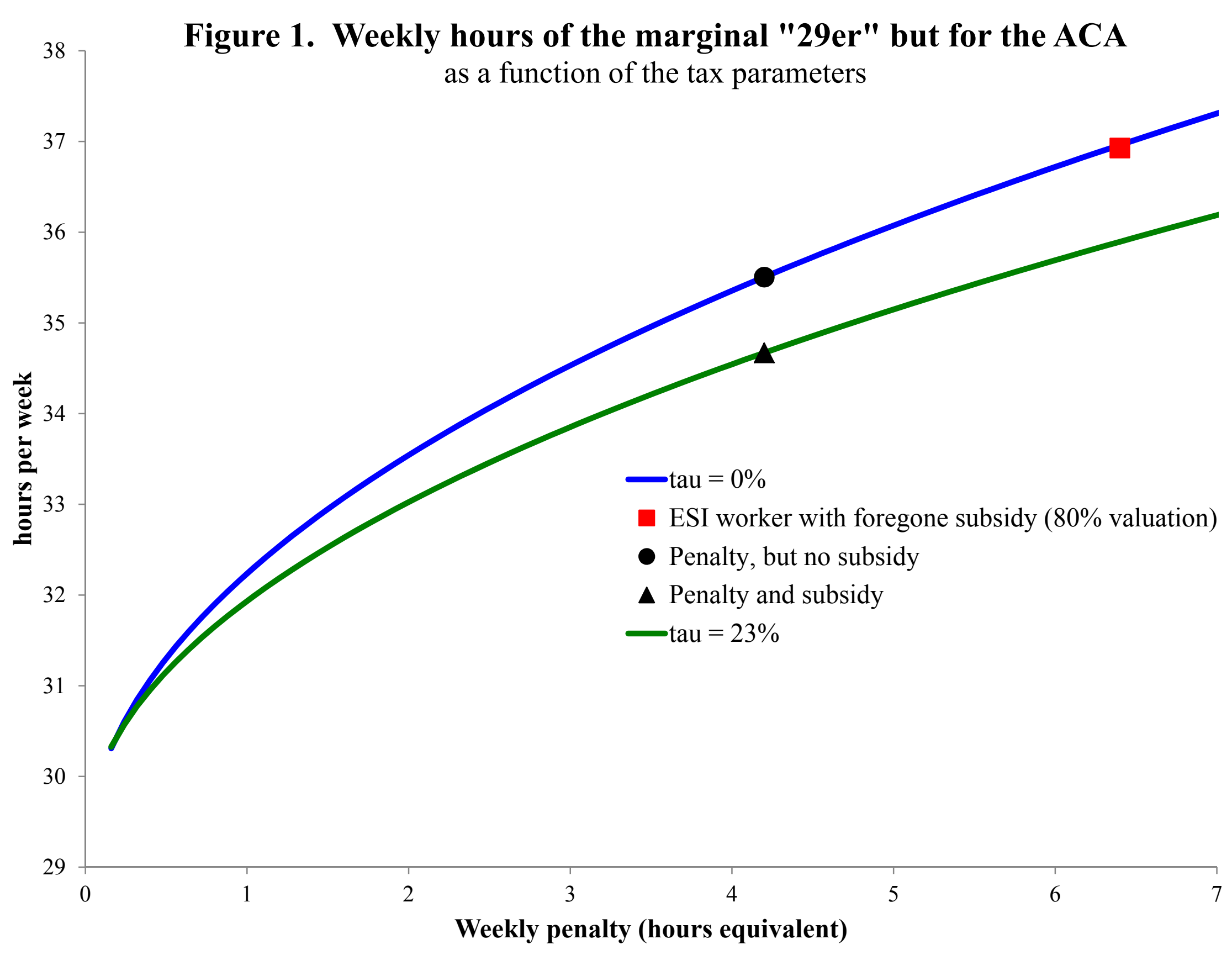




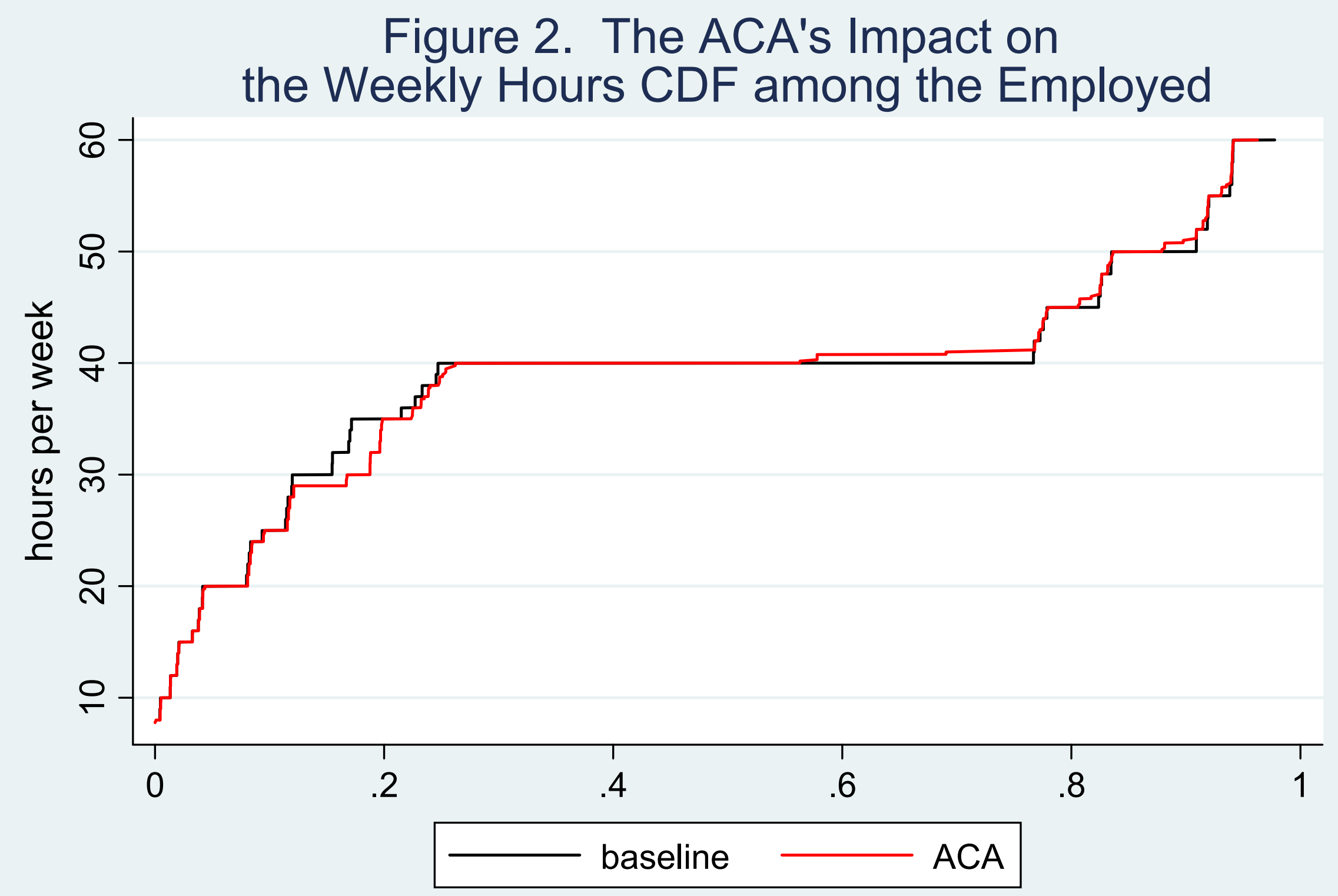

Note: ACA is the weighted average of all tax scenarios 
Figure 3. Employment and Hours Impacts in the Cross-Section

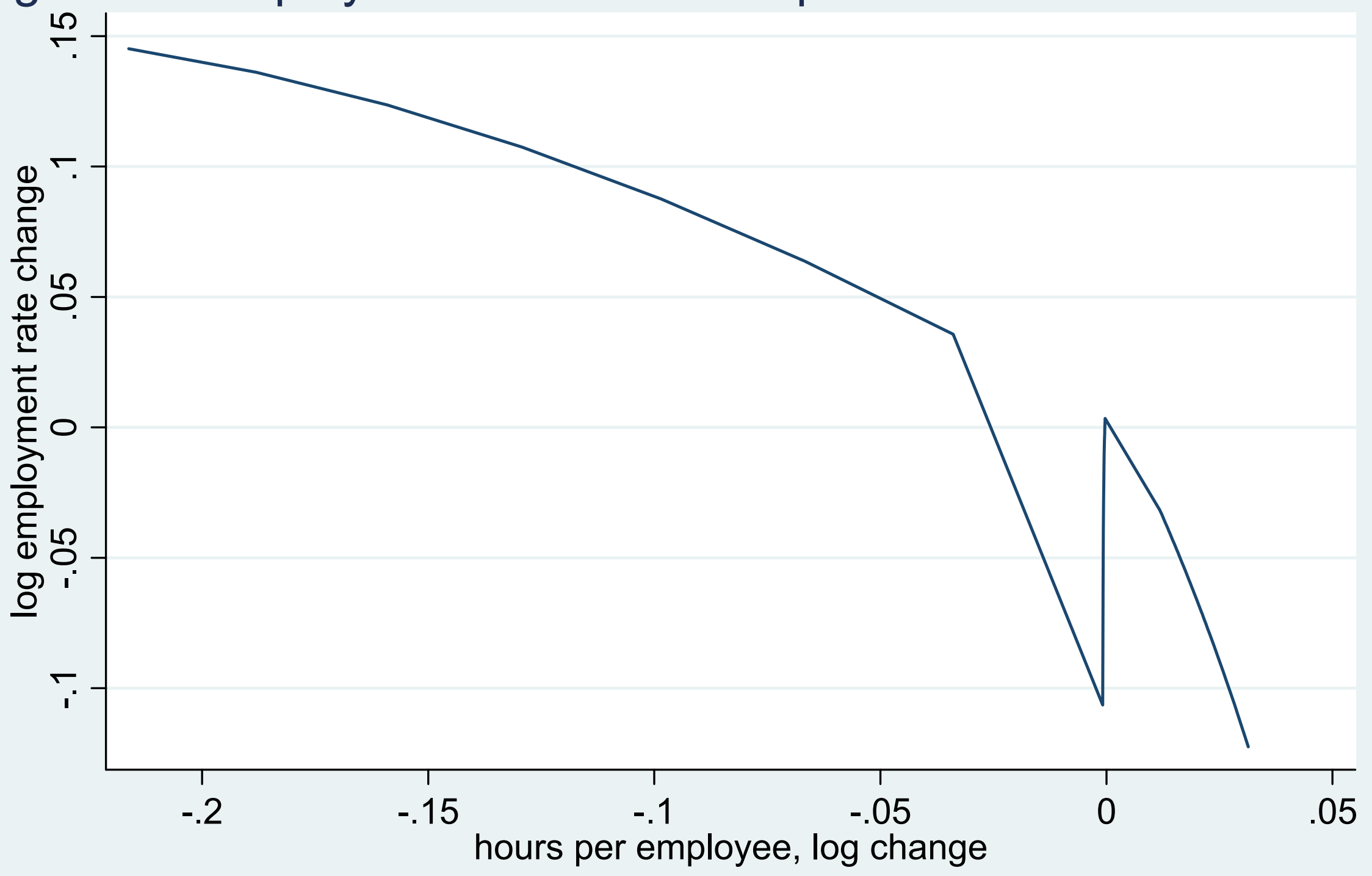

Note: only one ACA tax scenario is shown (subsidies foregone by ESI workers) 


\section{Figure 4a. The ACA's Impact on Weekly Hours CDFs among the Employed}

Two more common tax scenarios

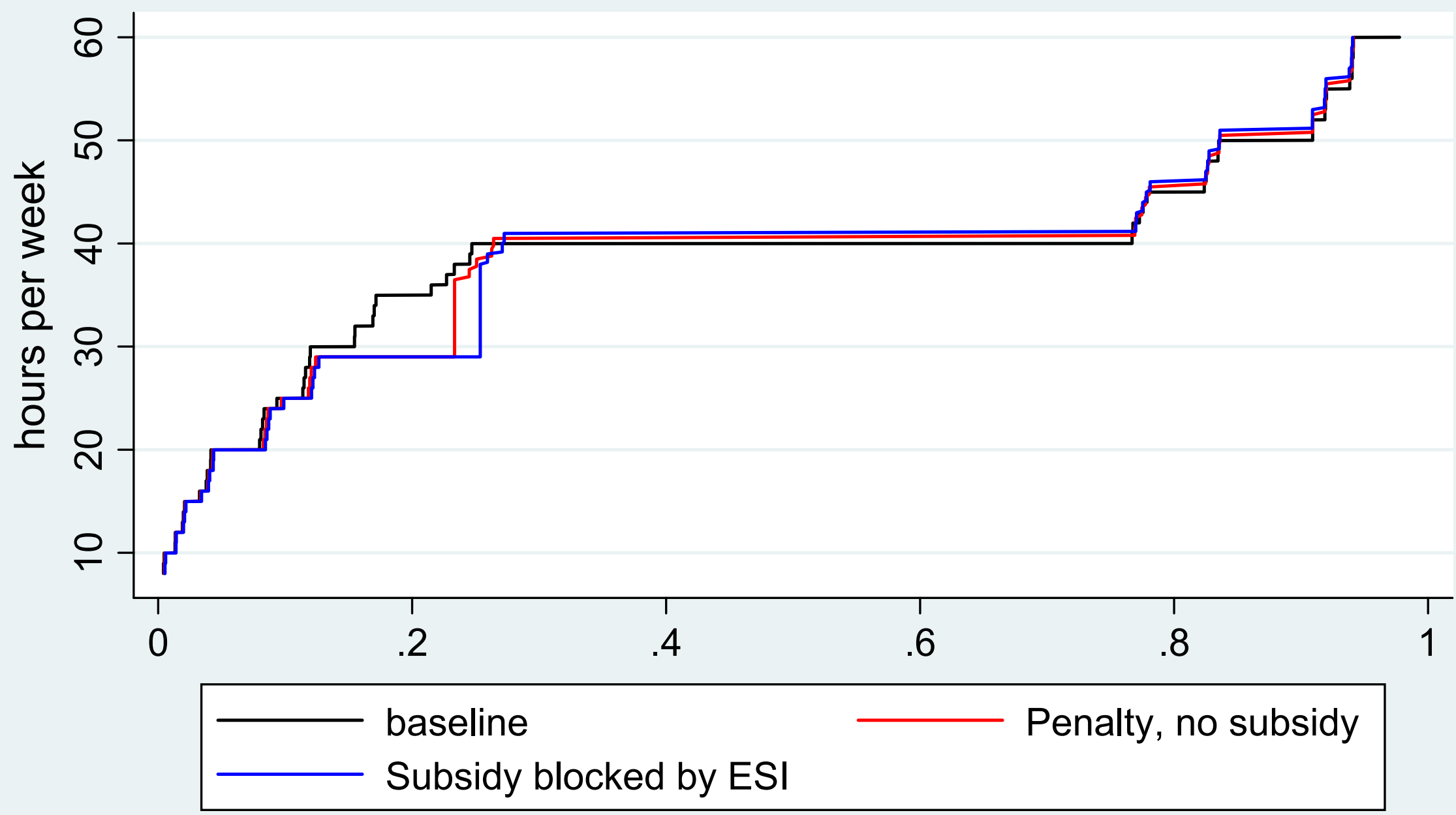

Note: only 2 of 4 ACA tax scenarios are shown 


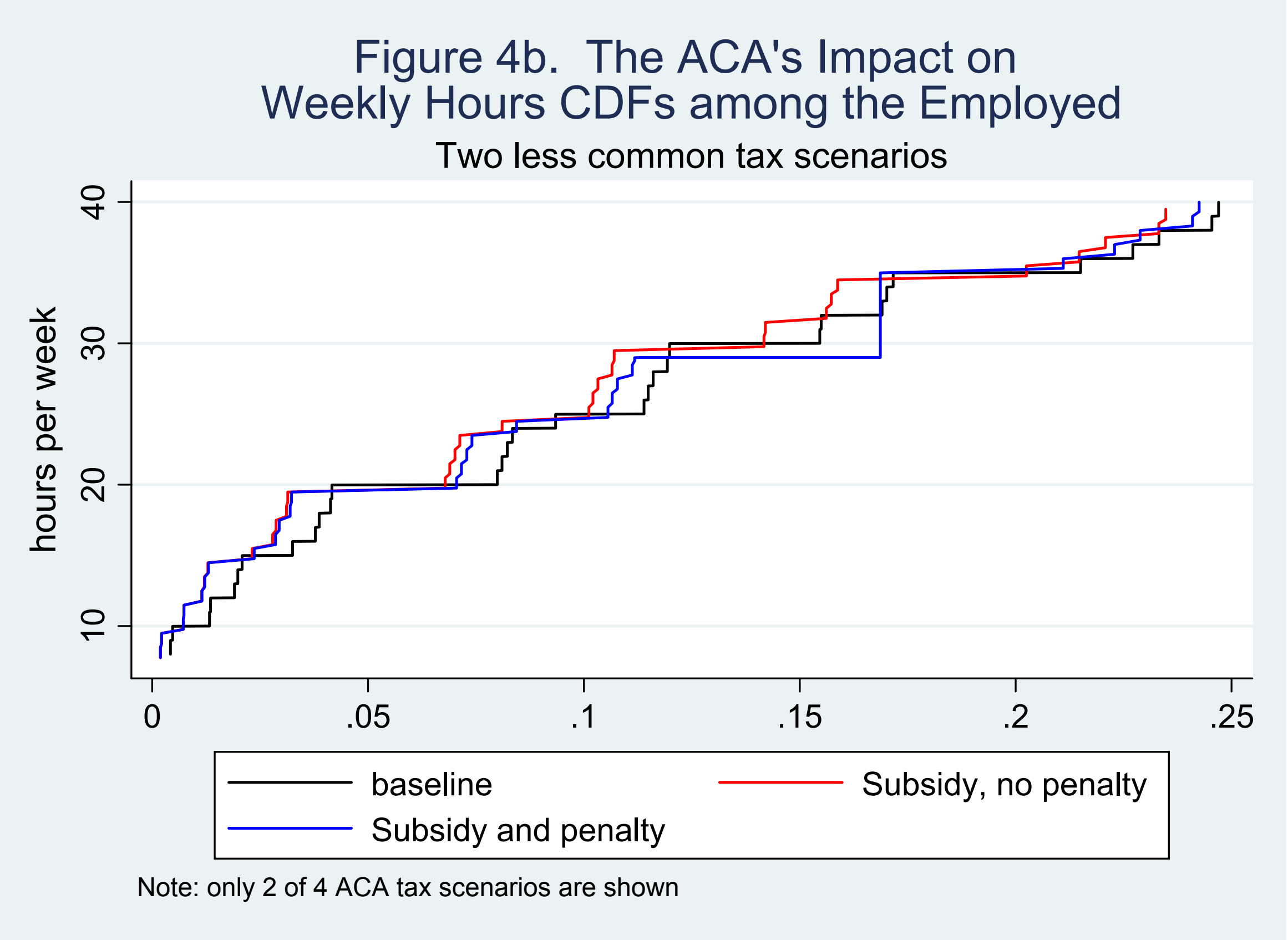




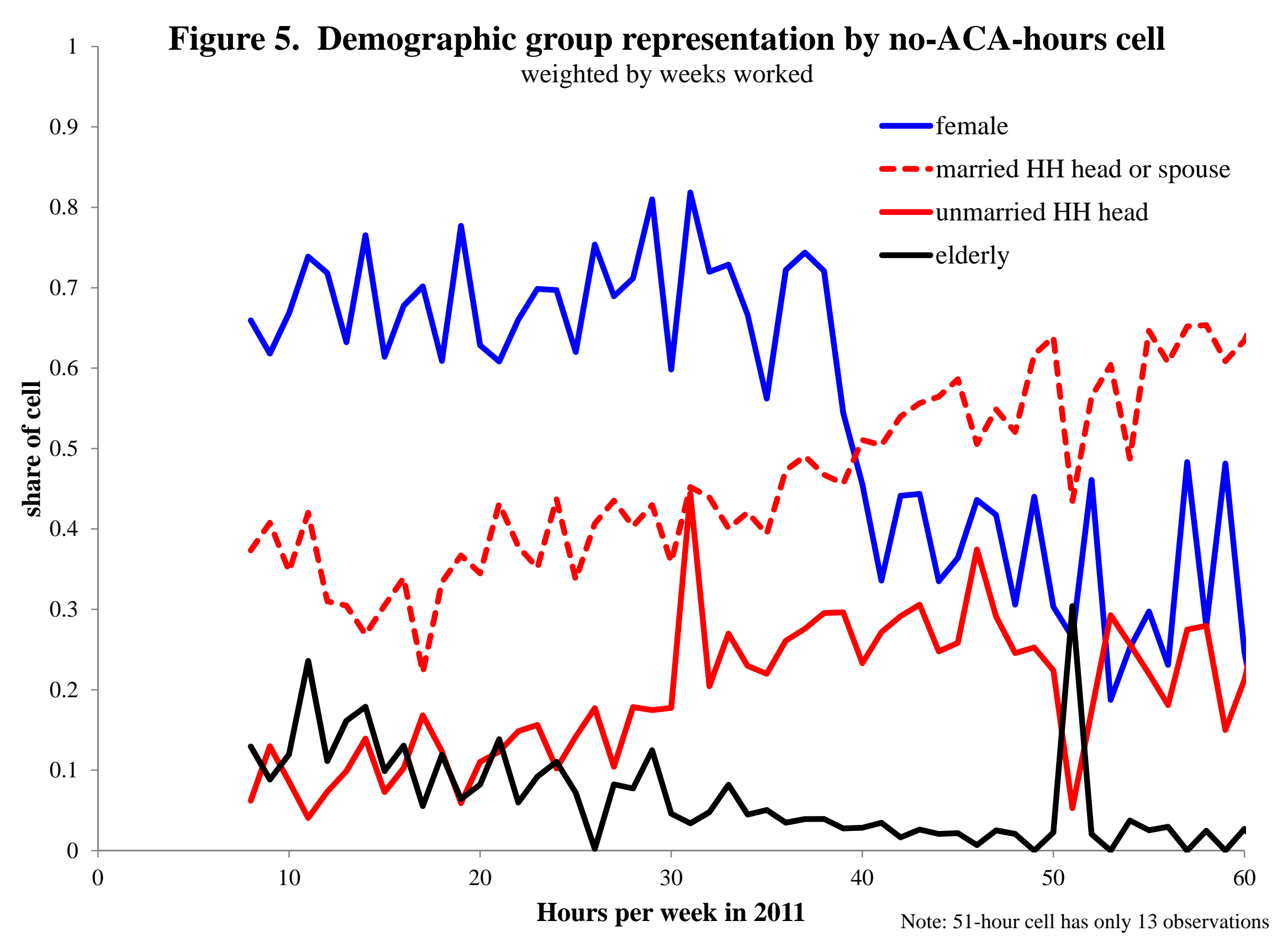




\section{Bibliography}

Burkhauser, Richard V., Sean Lyons, and Kosali I. Simon. "The Importance of the Meaning and Measurement of "Affordable" in the Affordable Care Act." NBER working paper, no. 17279 (September 2011).

Calmfors, Lars, and Michael Hoel. "Work Sharing and Overtime." Scandinavian Journal of Economics 90, no. 1 (March 1988): 45-62.

Dubay, Lisa, Sharon K. Long, and Emily Lawton. Will Health Reform Lead to Job Loss? Evidence from Massachusetts Says No. Urban Institute, 2012.

Gallen, Trevor S. "Size Provisions in the Affordable Care Act." manuscript, University of Chicago, 2013.

Gamage, David S. "Perverse Incentives Arising from the Tax Provisions of Healthcare Reform: Why Further Reforms are Needed to Prevent Avoidable Costs to Low- and ModerateIncome Workers." Tax Law Review 65, no. 4 (Summer 2012): 669-721.

Goolsbee, Austan. Testimony at the Hearing on the Health Care Law's Impact on Jobs, Employers, and the Economy. Washington, DC: Committee on Ways and Means, U.S. House of Representatives, 2011.

Gruber, Jonathan, and Brigitte C. Madrian. "Health Insurance, Labor Supply, and Job Mobility: A Critical Review of the Literature." In Health Policy and the Uninsured, edited by Catherine G. McLaughlin, 97-178. Washington, DC: Urban Institute Press, 2004.

Hamermesh, Daniel S. Labor Demand. Princeton, NJ: Princeton University Press, 1996a.

-. Workdays, Workhours, and Work Schedules. Kalamazoo, MI: Upjohn Institute for Employment Research, 1996b.

Hart, Robert A. Working Time and Employment. Winchester, MA: Allen \& Unwin, Inc., 1987.

Heim, Bradley T., and Ithai, Z. Lurie. "Does Health Reform Lead to Increased Job Mobility? Evidence from Massachusetts." manuscript, Indiana University, February 2014.

Hirsch, Barry T. "Why Do Part-time Workers Earn Less? The Role of Worker and Job Skills." Industrial and Labor Relations Review 58, no. 4 (July 2005): 525-51.

Montgomery, Mark, and James Cosgrove. "The Effect of Employee Benefits on the Demand for Part-Time Workers." Industrial and Labor Relations Review 47, no. 1 (1993): 87-98.

Mulligan, Casey B. "Average Marginal Tax Rates under the Affordable Care Act." NBER working paper, no. 19365 (November 2013a).

Mulligan, Casey B. "Is the Affordable Care Act Different from Romneycare? A Labor Economics Perspective." NBER working paper, no. 19366 (November 2013b).

Mulligan, Casey B. "The ACA: Some Unpleasant Welfare Arithmetic." NBER working paper, March 2014.

-. The Redistribution Recession. New York: Oxford University Press (redistributionrecession.com), 2012.

Mulligan, Casey B., and Trevor S. Gallen. "Wedges, Wages, and Productivity under the Affordable Care Act." NBER working paper, no. 19771 (December 2013).

Oi, Walter Y. "Labor as a Quasi-Fixed Factor." Journal of Political Economy 70, no. 6 (December 1962): 538-55.

Owen, John D. Working Hours: An Economic Analysis. Lexington, MA: Lexington Book, 1979. 
Rosen, Sherwin. "The Supply of Work Schedules and Employment." In Work Time and Employment. Washington, DC: National Commission for Manpower Policy, 1978.

United States Department of Treasury. "Shared Responsibility for Employers Regarding Health Coverage." ofr.gov. February 7, 2014. http://www.ofr.gov/OFRUpload/OFRData/201403082_PI.pdf (accessed February 12, 2014). 